\title{
Ribosomal Ribonucleic Acid Cistron Similarities of Phytopathogenic Pseudomonas Species
}

\author{
P. DE VOS, M. GOOR, M. GILLIS, AND J. DE LEY* \\ Laboratorium voor Microbiologie en microbiële Genetica, Rijksuniversiteit, B-9000 Gent, Belgium
}

\begin{abstract}
Deoxyribonucleic acid (DNA)-ribosomal ribonucleic acid (rRNA) hybridizations were carried out between 23S ${ }^{14} \mathrm{C}$ - or ${ }^{3} \mathrm{H}$-labeled rRNAs from type strains Pseudomonas fluorescens ATCC 13525, Pseudomonas acidovorans ATCC 15668, Pseudomonas solanacearum ATCC 11696, and Xanthomonas campestris NCPPB 528 and DNA from one or more strains of several taxonomically assigned or unassigned phytopathogenic Pseudomonas species. The strains were assigned to one of the following rRNA branches: (i) the $P$. fluorescens rRNA branch (the authentic pseudomonads), containing also Pseudomonas agarici, Pseudomonas amygdali, Pseudomonas asplenii, Pseudomonas caricapapayae, Pseudomonas cichorii, Pseudomonas corrugata, Pseudomonas fuscovaginae, Pseudomonas marginalis (P. marginalis pathovar marginalis, $P$. marginalis pathovar alfalfae, and $P$. marginalis pathovar pastinacae), Pseudomonas meliae, the Pseudomonas syringae group (including "Pseudomonas aceris," "Pseudomonas antirrhini," "Pseudomonas apii," "Pseudomonas berberidis," "Pseudomonas cannabina," "Pseudomonas coronafaciens", “Pseudomonas eriobotryae," "Pseudomonas lapsa," "Pseudomonas maculicola," "Pseudomonas oryzicola," "Pseudomonas panici," "Pseudomonas passiflorae," "Pseudomonas primulae," "Pseudomonas ribicola," "Pseudomonas sesami," "Pseudomonas striafaciens," P. syringae, "Pseudomonas ulmi," and 'Pseudomonas viburni"), Pseudomonas tolaasii, Pseudomonas viridiflava, and "Pseudomonas washingtoniae;"' (ii) the $P$. solanacearum rRNA branch, containing $P$. solanacearum, Pseudomonas andropogonis (synonym, “Pseudomonas stizolobii"), Pseudomonas caryophylli, Pseudomonas cepacia, Pseudomonas gladioli (synonyms, "Pseudomonas alliicola" and "Pseudomonas marginata'), Pseudomonas glumae, Pseudomonas rubrisubalbicans, and Pseudomonas woodsii; (iii) the P. acidovorans rRNA branch, containing also "Pseudomonas alboprecipitans" (synonym of Pseudomonas avenae), Pseudomonas pseudoalcaligenes subsp. citrulli, Pseudomonas rubrilineans, and "Pseudomonas setariae;" and (iv) the Xanthomonas rRNA branch, containing X. campestris, Pseudomonas betle, "Pseudomonas gardneri," Pseudomonas hibiscicola, "Pseudomonas mangiferaeindicae," "Pseudomonas viticola," and "Pseudomonas vitiswoodrowii." Pseudomonas flectens and Pseudomonas cissicola definitely have to be removed from the genus Pseudomonas. Pseudomonas cattleyae, and "Pseudomonas viridilivida" are heterogeneous and require additional examination.
\end{abstract}

The genus Pseudomonas, as defined in Bergey's Manual of Determinative Bacteriology, 8th ed. (23), and Bergey's Manual of Systematic Bacteriology (57), consists of a very large and heterogeneous assemblage of polarly flagellated gram-negative bacteria. Valuable phenotypic studies on the taxonomy within this genus were carried out by several workers $(34,35,44,69,70)$. The extensive phenotypic characterization of a large number of Pseudomonas strains by Stanier et al. (84) resulted in improved classification into species and species groups.

Additional approaches have been used to clarify the relationships among the taxa in the genus Pseudomonas. In general, deoxyribonucleic acid (DNA) base compositions (mean molar percent guanine plus cytosine $[G+C])(46)$ and the results of DNA-DNA hybridization (58) agreed with the phenotypic classification scheme. DNA-ribosomal ribonucleic acid (rRNA) hybridization (59) revealed the existence of five rRNA homology groups of named Pseudomonas. These findings were supported by the results of immunological characterization of the host factor required for coliphage $\mathrm{Q} \beta$ ribonucleic acid replication (24), the results of cellular fatty acid composition studies (36), and enzymic data (15).

Recently, De Vos and De Ley (22) confirmed the existence of the same five rRNA groups by using another DNA-rRNA hybridization technique. However, by including many more strains and in particular many strains of a great variety of gram-negative taxa, these authors found that

\footnotetext{
* Corresponding author.
}

these rRNA groups are less related to each other than they are to other gram-negative genera (Fig. 1). Therefore, De Vos and De Ley rejected the present classification of Pseudomonas species in a single genus. The following division was proposed: (i) the Pseudomonas fluorescens rRNA branch, which De Vos and De Ley considered to be the authentic genus Pseudomonas, containing the type species, Pseudomonas aeruginosa (this branch corresponds to Section I of Pseudomonas in Bergey's Manual of Systematic Bacteriology [57]); (ii) the Pseudomonas acidovorans rRNA branch, corresponding to Section III of Pseudomonas (57); (iii) the Pseudomonas solanacearum rRNA branch, corresponding to Section II of Pseudomonas (57) (the latter two branches should be removed from the genus Pseudomonas); (iv) the Xanthomonas rRNA branch, containing "Pseudomonas" maltophilia, which has been reclassified as Xanthomonas maltophilia (89); and (v) Pseudomonas vesicularis and Pseudomonas diminuta, which do not belong in the genus Pseudomonas at all.

A great number of phytopathogenic $P$ seudomonas species have been created by using the so-called new host-new species concept. Because of poor descriptions, a limited number of these species were accepted on the Approved Lists of Bacterial Names (81), on the Validation Lists, and by publication in the International Journal of Systematic Bacteriology since 1980. A great number have not yet been officially accepted, although they have important phytopathological and economic properties $(26,102)$. A certain number of phytopathogenic Pseudomonas species have been 


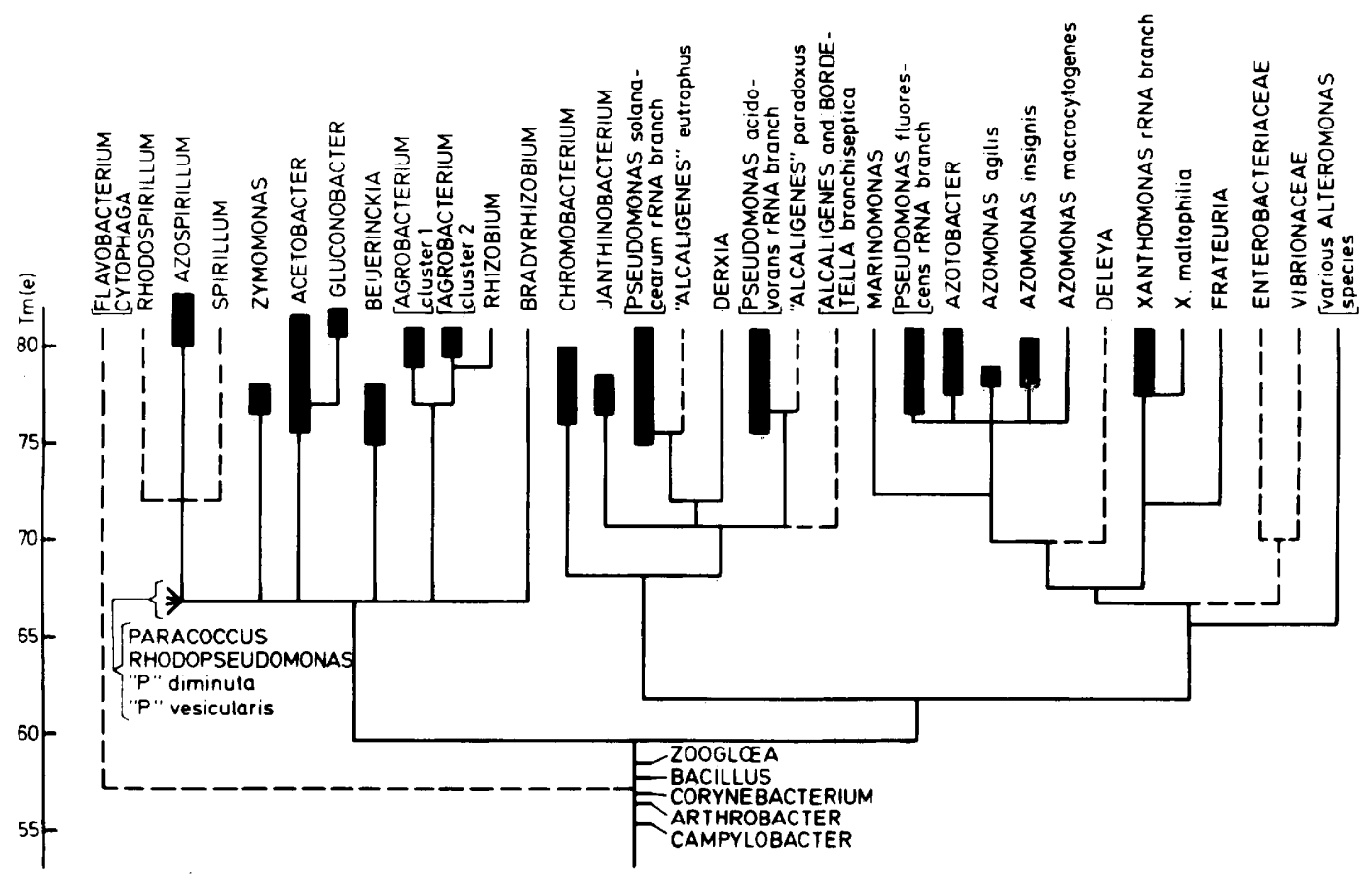

FIG. 1. rRNA cistron similarity dendrogram of various gram-negative bacteria, based on $T_{m(e)}$ values (in degrees Celsius) of DNA-rRNA hybrids. All data were determined by members of our research group. The solid bars indicate the $T_{m(e)}$ ranges within individual rRNA branches. The branching levels were calculated from previously published data $(18,20-22,30,89,90,97)$, as well as from unpublished data (dotted lines) obtained by our research group by using the unweighted average pair group method.

assigned to taxonomic positions within the framework of Bergey's Manual of Determinative Bacteriology, 8th ed. (23), and Bergey's Manual of Systematic Bacteriology (57); others still remain taxonomically unattached (e.g., those listed in the Addenda I and III of Bergey's Manual of Determinative Bacteriology, 8th ed. [23], and in Section V of Bergey's Manual of Systematic Bacteriology [57]). Division into a fluorescent group and a nonfluorescent group (102) has been proposed for practical identification purposes.

From our previous DNA-rRNA hybridization experiments (22) it appeared that phytopathogenic Pseudomonas species belong in different rRNA branches. It was the purpose of the study described here to determine the correct taxonomic positions at the generic and subgeneric levels of a large number of the above-mentioned phytopathogenic Pseudomonas species and strains by means of DNA-rRNA hybridization.

\section{MATERIALS AND METHODS}

Bacterial strains. The strains which we used are listed in Table 1. For practical reasons, in our discussion below we use the original species names as they appear in Table 1. For mass cultures, the bacteria were grown in Roux flasks on media solidified with 2 to $2.5 \%$ agar. The compositions of the media used have been described previously $(18,20-22,30$, 99). When different colony types were isolated from the subcultures which we received, they were kept as separate strains only when the electropherograms of their soluble cell proteins were different.

Preparation of labeled rRNA and DNA and hybridization conditions. rRNAs labeled with ${ }^{14} \mathrm{C}$ or ${ }^{3} \mathrm{H}$ were prepared from type strains $P$. fluorescens ATCC $13525, P$. acidovorans ATCC 15668, P. solanacearum ATCC 11696, and Xanthomonas campestris NCPPB 528 as described previously (22). For all DNA preparations except one we used the methods described previously (22); for the preparation of DNA from the type strain of "Pseudomonas viridilivida," strain NCPPB 1963, we treated the DNA with lysozyme and $n$-dodecylamine in sucrose-TES 4 [0.1 M tris(hydroxymethyl)aminomethane-hydrochloride $(\mathrm{pH} 8.0)$ with 0.07 disodium ethylenediaminetetraacetic acid and $0.05 \mathrm{M} \mathrm{NaCl}]$ as described by Meynell (48). The methods used for the preparation of high-molecular-weight DNA were those used by De Vos and De Ley (22), whereas the methods used for fixation of single-stranded high-molecular-weight DNA on membrane filters, saturation hybridization between ${ }^{14} \mathrm{C}$ - or ${ }^{3} \mathrm{H}$ - labeled rRNA and filter-fixed DNA, determination of the thermal stability of the hybrids, and quantitative chemical determination of the DNA on the filters were the methods used by De Ley and De Smedt (17); these methods have been used previously in studies done by workers in our laboratory $(18,20,21,30,89,90,97)$.

Average molar percent $\mathbf{G}+\mathbf{C}$. Average DNA base compositions either were determined or were taken from previous papers. We used the methods described previously (22). The data are shown in Table 2.

\section{RESULTS AND DISCUSSION}

The results of the DNA-rRNA hybridizations are shown in Table 2. The hybrids were characterized by the following two parameters: the temperature at which $50 \%$ of the hybrid was eluted (the $T_{m(e)}$ value) and the percentage of rRNA binding (i.e., the amount of labeled rRNA bound after ribonuclease treatment per $100 \mu \mathrm{g}$ of DNA retained on the filter). For each labeled reference rRNA, the $T_{m(e)}$ values were plotted versus the percentages of rRNA binding on what we call an rRNA similarity map (Fig. 2 through 5). The $T_{m(e)}$ value is the most decisive taxonomic parameter discussed extensively in our previous papers $(18,21,22)$. The 
TABLE 1. Organisms used and their nomenclatural status, strain numbers, origins and growth media

\begin{tabular}{|c|c|c|c|c|c|c|c|}
\hline \multirow[b]{2}{*}{$\begin{array}{l}\text { Sequence } \\
\text { no. }\end{array}$} & \multirow[b]{2}{*}{$\begin{array}{l}\text { Species name as } \\
\text { originally described }^{a}\end{array}$} & \multirow[b]{2}{*}{$\begin{array}{l}\text { Name according to } \\
\text { Young et al. } .^{b}\end{array}$} & \multicolumn{2}{|c|}{ Classification in: } & \multirow[b]{2}{*}{ Strain } & \multirow[b]{2}{*}{$\begin{array}{l}\text { Host plant or origin and } \\
\text { place and year of isolation }\end{array}$} & \multirow[b]{2}{*}{$\begin{array}{l}\text { Growth } \\
\text { medium }\end{array}$} \\
\hline & & & $\begin{array}{c}\text { Bergey's } \\
\text { Manual of } \\
\text { Determinative } \\
\text { Bacteriology, } \\
\text { 8th ed. }\end{array}$ & $\begin{array}{c}\text { Bergey's } \\
\text { Manual of } \\
\text { Systematic } \\
\text { Bacteri- } \\
\text { ology }\end{array}$ & & & \\
\hline 1 & "P. aceris" (1) & $\begin{array}{l}P \text {. syringae } \\
\text { pathovar aceris }\end{array}$ & Addendum I & Section I & NCPPB $958^{d}$ & $\begin{array}{l}\text { Acer sp., United States, } \\
\text { year unknown }\end{array}$ & B \\
\hline 2 & $\begin{array}{l}\text { P. acidovorans (AL) } \\
\text { (19) }\end{array}$ & & Section III & $\begin{array}{l}\text { Section } \\
\text { III }\end{array}$ & ATCC $15668^{\mathrm{Te}}$ & $\begin{array}{l}\text { Acetamide-enriched soil, } \\
\text { Holland, } 1926\end{array}$ & B \\
\hline 3 & $P . \operatorname{agarici}(\mathrm{AL})(100)$ & P. agarici & & Section V & NCPPB 1999t1 & $\begin{array}{l}\text { Agaricus bisporus } \\
\text { United Kingdom, } 1966\end{array}$ & $\mathrm{Z} 5$ \\
\hline 4 & P. agarici $(\mathrm{AL})(100)$ & & & & NCPPB $2289^{\mathrm{T}}$ & $\begin{array}{l}\text { Agaricus bisporus, New } \\
\text { Zealand, } 1969\end{array}$ & Z5 \\
\hline 5 & $P . \operatorname{agarici}(\mathrm{AL})(100)$ & & & & NCPPB $2471 \mathrm{t} 1$ & $\begin{array}{l}\text { Agaricus bisporus, } \\
\text { United Kingdom, } 1972\end{array}$ & $\mathrm{Z5}$ \\
\hline 6 & $P . \operatorname{agarici}(\mathrm{AL})(100)$ & & & & NCPPB 2471t2 & $\begin{array}{l}\text { Agaricus bisporus, } \\
\text { United Kingdom, } 1972\end{array}$ & $\mathrm{Z} 5$ \\
\hline 7 & $\begin{array}{l}\text { "P. alboprecipitans" } \\
(73)\end{array}$ & P. avenae & Addendum I & Section V & NCPPB $1011^{\mathrm{T}}$ & $\begin{array}{l}\text { Zea mays, United } \\
\text { States, } 1958\end{array}$ & B \\
\hline 8 & $\begin{array}{l}\text { "P. alboprecipitans" } \\
\text { (73) }\end{array}$ & & & & NCPPB 2399 & $\begin{array}{l}\text { Oryza sativa, } \\
\text { Philippines, year } \\
\text { unknown }\end{array}$ & Z5 \\
\hline 9 & $\begin{array}{l}\text { "P. alboprecipitans" } \\
(73)\end{array}$ & & & & NCPPB 2401 & Zea mays, Japan, 1966 & $\mathrm{Z5}$ \\
\hline 10 & "P. alliicola" (12) & $\begin{array}{l}P . \text { gladioli pathovar } \\
\text { alliicola }\end{array}$ & Section II & Section II & NCPPB $947^{d}$ & $\begin{array}{l}\text { Host plant unknown, } \\
\text { United States, } 1939\end{array}$ & $\mathrm{Z5}$ \\
\hline 11 & $\begin{array}{l}\text { P. amygdali }(\mathrm{AL}) \\
(66)\end{array}$ & P. amygdali & & Section V & NCPPB $2607^{\mathrm{T}}$ & $\begin{array}{l}\text { Prunus dulcis, Greece, } \\
\quad 1967\end{array}$ & $\mathrm{Z3}$ \\
\hline 12 & $\begin{array}{l}\text { P. amygdali }(\mathrm{AL}) \\
(66)\end{array}$ & & & & NCPPB 2608 & $\begin{array}{l}\text { Prunus dulcis, Greece, } \\
\quad 1967\end{array}$ & Z3 \\
\hline 13 & $\begin{array}{l}\text { P. amygdali }(\mathrm{AL}) \\
(66)\end{array}$ & & & & NCPPB 2610 & $\begin{array}{l}\text { Prunus dulcis, Greece, } \\
\quad 1968\end{array}$ & $\mathrm{Z3}$ \\
\hline 14 & $\begin{array}{l}\text { P. andropogonis } \\
\text { (AL) (83) }\end{array}$ & $P$. andropogonis & Addendum I & Section V & NCPPB 933 & $\begin{array}{l}\text { Zea mays, United } \\
\text { States, } 1959\end{array}$ & B \\
\hline 15 & $\begin{array}{l}P . \text { andropogonis } \\
\text { (AL) (83) }\end{array}$ & & & & NCPPB $934^{\mathrm{T}}$ & $\begin{array}{l}\text { Sorghum bicolor, United } \\
\quad \text { States, } 1959\end{array}$ & B \\
\hline 16 & "P. antirrhini" (91) & $\begin{array}{l}P \text {. syringae } \\
\text { pathovar } \\
\text { antirrhini }\end{array}$ & & Section I & NCPPB 1761 & $\begin{array}{l}\text { Antirrhinum majus, } \\
\text { United Kingdom, } 1965\end{array}$ & B \\
\hline 17 & "P apii" (37) & $\begin{array}{l}P \text {. syringae } \\
\text { pathovar apii }\end{array}$ & Addendum I & Section I & NCPPB $1626^{d}$ & $\begin{array}{l}\text { Apium graveolens var. } \\
\text { dulce, United States, } \\
1942\end{array}$ & B \\
\hline 18 & P. asplenii (AL) (4) & P. asplenii & Addendum I & Section V & NCPPB $1947^{T}$ & $\begin{array}{l}\text { Asplenium nidus, place } \\
\text { and year of isolation } \\
\text { unknown }\end{array}$ & B \\
\hline 19 & "P. berberidis" (95) & $\begin{array}{l}P . \text { syringae } \\
\text { pathovar } \\
\text { berberidis }\end{array}$ & Addendum I & Section I & NCPPB 1871 & $\begin{array}{l}\text { Berberis thunbergii, } \\
\text { United States, } 1942\end{array}$ & $\mathrm{Z5}$ \\
\hline 20 & "P. berberidis" (95) & & & & NCPPB $2724^{d}$ & $\begin{array}{l}\text { Berberis sp., New } \\
\text { Zealand, } 1972\end{array}$ & $\mathrm{Z5}$ \\
\hline 21 & P. betle (AL) (67) & $P$. betle & $\begin{array}{l}\text { Addendum } \\
\text { III }\end{array}$ & & NCPPB $323^{\top}$ & $\begin{array}{l}\text { Piper betle, Sri Lanka, } \\
1953\end{array}$ & B \\
\hline 22 & "P. cannabina" (86) & $\begin{array}{l}P . \text { syringae } \\
\text { pathovar } \\
\text { cannabina }\end{array}$ & Addendum I & Section I & NCPPB 1410 & $\begin{array}{r}\text { Cannabis sativa, } \\
\text { Hungary, } 1957\end{array}$ & B \\
\hline 23 & “P. cannabina" (86) & & & & NCPPB 2069 & $\begin{array}{l}\text { Cannabis sativa, } \\
\text { Yugoslavia, year } \\
\text { unknown }\end{array}$ & Z5 \\
\hline 24 & $\begin{array}{l}\text { P. caricapapayae } \\
\text { (AL) (71) }\end{array}$ & $P$. caricapapayae & & Section V & NCPPB 1872 & $\begin{array}{l}\text { Carica papaya, Brazil, } \\
\quad 1955\end{array}$ & B \\
\hline 25 & $\begin{array}{l}\text { P. caricapapayae } \\
\text { (AL) (71) }\end{array}$ & & & & NCPPB $1873^{\mathrm{T}}$ & $\begin{array}{l}\text { Carica papaya, Brazil, } \\
\quad 1966\end{array}$ & $\mathrm{Z5}$ \\
\hline 26 & $\begin{array}{l}\text { P. caryophylli (AL) } \\
\text { (12) }\end{array}$ & P. caryophylli & Section II & Section II & NCPPB 349 & $\begin{array}{l}\text { Dianthus caryophyllus, } \\
\text { Denmark, year } \\
\text { unknown }\end{array}$ & PAF \\
\hline 27 & $\begin{array}{l}\text { P. caryophylli (AL) } \\
\text { (12) }\end{array}$ & & & & NCPPB 609 & $\begin{array}{l}\text { Dianthus caryophyllus, } \\
\text { United Kingdom, } 1958\end{array}$ & $\mathrm{Z3}$ \\
\hline 28 & $\begin{array}{l}\text { P. caryophylli (AL) } \\
\text { (12) }\end{array}$ & & & & NCPPB $2151^{\mathrm{T}}$ & $\begin{array}{l}\text { Dianthus caryophyllus, } \\
\text { United States, } 1951\end{array}$ & $\mathrm{Z5}$ \\
\hline 29 & $\begin{array}{l}P . \text { cattleyae (AL) } \\
\text { (63) }\end{array}$ & P. cattleyae & Addendum I & Section V & NCPPB $961^{T}$ & Unknown & $\mathrm{Z5}$ \\
\hline
\end{tabular}


TABLE 1-Continued

\begin{tabular}{|c|c|c|c|c|c|c|c|}
\hline \multirow[b]{2}{*}{$\begin{array}{l}\text { Sequence } \\
\text { no. }\end{array}$} & \multirow[b]{2}{*}{$\begin{array}{l}\text { Species name as } \\
\text { originally described }^{a}\end{array}$} & \multirow[b]{2}{*}{$\begin{array}{l}\text { Name according to } \\
\text { Young et al. } .^{b}\end{array}$} & \multicolumn{2}{|c|}{ Classification in: } & \multirow[b]{2}{*}{ Strain } & \multirow[b]{2}{*}{$\begin{array}{l}\text { Host plant or origin and } \\
\text { place and year of isolation }\end{array}$} & \multirow[b]{2}{*}{$\begin{array}{l}\text { Growth } \\
\text { medium }\end{array}$} \\
\hline & & & $\begin{array}{l}\text { Bergey's } \\
\text { Manual of } \\
\text { Determinative } \\
\text { Bacteriology, } \\
\text { 8th ed. }\end{array}$ & $\begin{array}{c}\text { Bergey's } \\
\text { Manual of } \\
\text { Systematic } \\
\text { Bacteri- } \\
\text { ology }\end{array}$ & & & \\
\hline 30 & $\begin{array}{l}P .{ }_{(63)}^{\text {cattleyae }}(\mathrm{AL}) \\
\end{array}$ & & & & NCPPB 1874 & $\begin{array}{l}\text { Phalaenopsis sp., United } \\
\text { States, } 1950\end{array}$ & Z5 \\
\hline 31 & $\begin{array}{l}\text { P. cattleyae (AL) } \\
(63)\end{array}$ & & & & PDDCC 3992 & $\begin{array}{l}\text { Cattleya sp., United } \\
\text { States, year unknown }\end{array}$ & PAF \\
\hline 32 & P. cepacia $(\mathrm{VL})(13)$ & P. cepacia & Section II & Section II & Ballard $717^{\mathrm{T}}$ & $\begin{array}{l}\text { Allium cepa, place and } \\
\text { year of isolation } \\
\text { unknown }\end{array}$ & Z5 \\
\hline 33 & $P$. cepacia (VL) (13) & & & & Stanier 382 & $\begin{array}{l}\text { Forest soil, Trinidad, } \\
1958\end{array}$ & B \\
\hline 34 & $P$. cepacia (VL) (13) & & & & NCTC 10661 & $\begin{array}{l}\text { Forest soil, Trinidad, } \\
1958\end{array}$ & $\mathrm{Z5}$ \\
\hline 35 & P. cichorii (AL) (88) & P. cichorii & Section I & Section I & NCPPB 906 & $\begin{array}{l}\text { Chrysanthemum } \\
\text { morifolium, United } \\
\text { States, } 1957\end{array}$ & B \\
\hline 36 & P. cichorii (AL) (88) & & & & NCPPB $943^{\mathrm{T}}$ & $\begin{array}{l}\text { Cichorium endivia, } \\
\text { Germany, } 1929\end{array}$ & $\mathrm{Z} 5$ \\
\hline 37 & P. cichorii (AL) (88) & & & & NCPPB 1512 & $\begin{array}{l}\text { Chrysanthemum } \\
\text { morifolium, United } \\
\text { States, } 1962\end{array}$ & B \\
\hline 38 & $P$. cissicola (AL) (93) & P. cissicala & $\begin{array}{l}\text { Addendum } \\
\text { III }\end{array}$ & Section V & NCPPB $2982^{\mathrm{T}}$ & $\begin{array}{l}\text { Cissus japonica, Japan, } \\
1974\end{array}$ & Z5 \\
\hline 39 & P. cissicola (AL) (93) & & & & PDDCC 4290 & $\begin{array}{l}\text { Cissus japonica, Japan, } \\
1974\end{array}$ & PAF \\
\hline 40 & $\begin{array}{l}\text { "P. caronafaciens" } \\
(27)\end{array}$ & $\begin{array}{l}P . \text { syringae } \\
\text { pathovar } \\
\text { coronafaciens }\end{array}$ & Section I & Section I & NCPPB 1328 & $\begin{array}{l}\text { Bromus sp., Canada, } \\
\quad 1962\end{array}$ & $\mathrm{Z5}$ \\
\hline 41 & $\begin{array}{l}\text { P. corrugata }(\mathrm{VL}) \\
\quad(75)\end{array}$ & P. corrugata & & Section V & NCPPB $2445^{\mathrm{T}}$ & $\begin{array}{l}\text { Lycopersicon } \\
\text { lycopersicum, United } \\
\text { Kingdom, } 1972\end{array}$ & $\mathrm{Z} 5$ \\
\hline 42 & $\begin{array}{l}P . \text { corrugata }(\mathrm{VL}) \\
\text { (75) }\end{array}$ & & & & NCPPB 2447 & $\begin{array}{l}\text { Lycopersicon } \\
\text { lycopersicum, United } \\
\text { Kingdom, } 1972\end{array}$ & PAF \\
\hline 43 & $\begin{array}{l}\text { P. corrugata (VL) } \\
\text { (75) }\end{array}$ & & & & NCPPB 2455 & $\begin{array}{l}\text { Lycopersicon } \\
\text { lycopersicum, United } \\
\text { Kingdom, } 1972\end{array}$ & $\mathrm{Z} 5$ \\
\hline 44 & $\begin{array}{l}\text { "P. eriobotryae" } \\
(92)\end{array}$ & $\begin{array}{l}\text { P. syringae } \\
\text { pathovar } \\
\text { eriobotryae }\end{array}$ & Addendum I & Section I & NCPPB $2331^{d}$ & $\begin{array}{l}\text { Eriobotrya japonica, } \\
\text { United States, } 1970\end{array}$ & $\mathrm{Z5}$ \\
\hline 45 & P. flectens (AL) (38) & P. flectens & Addendum I & & NCPPB 538 & $\begin{array}{l}\text { Phaseolus vulgaris, } \\
\text { Australia, } 1957\end{array}$ & PAF \\
\hline 46 & P. flectens (AL) (38) & & & & NCPPB $539^{\mathrm{T}}$ & $\begin{array}{l}\text { Phaseolus vulgaris, } \\
\text { Australia, } 1956\end{array}$ & $\mathrm{Z3}$ \\
\hline 47 & $\begin{array}{l}\text { P. fuorescens (AL) } \\
\text { (49) }\end{array}$ & & Section I & Section I & ATCC $13525^{\mathrm{T}}$ & $\begin{array}{l}\text { Prefilter tanks, United } \\
\quad \text { Kingdom, } 1951\end{array}$ & B \\
\hline 48 & $\begin{array}{l}\text { P. fuscovaginae } \\
\text { (VL) (51) }\end{array}$ & & & & PDDCC 5939 & $\begin{array}{l}\text { Oryza sativa, Japan, } \\
\text { year unknown }\end{array}$ & PAF \\
\hline 49 & "P. gardneri" (85) & & & & NCPPB $881^{f}$ & $\begin{array}{l}\text { Lycopersicon } \\
\text { lycopersicum, } \\
\text { Yugoslavia, } 1953\end{array}$ & B \\
\hline 50 & P. gladioli (AL) (80) & $\begin{array}{l}P . \text { gladioli pathovar } \\
\text { gladioli }\end{array}$ & Section II & Section II & NCPPB $1891^{\mathrm{T}}$ & $\begin{array}{l}\text { Gladiolus sp., United } \\
\text { States, year unknown }\end{array}$ & $\mathrm{Z} 5$ \\
\hline 51 & P. glumae (AL) (40) & P. glumae & & Section V & NCPPB 2391 & $\begin{array}{l}\text { Oryza sativa, Japan, } \\
1967\end{array}$ & $\mathrm{Z5}$ \\
\hline 52 & P. glumae (AL) (40) & & & & NCPPB $2981^{\mathrm{T}}$ & $\begin{array}{l}\text { Oryza sativa, Japan, } \\
1967\end{array}$ & $\mathrm{Z5}$ \\
\hline 53 & $\begin{array}{l}\text { P. hibiscicola (AL) } \\
(52)\end{array}$ & P. hibiscicola & Addendum I & & NCPPB $1683^{\mathrm{T}}$ & $\begin{array}{l}\text { Hibiscus rosasinensis, } \\
\text { India, } 1964\end{array}$ & B \\
\hline 54 & "P. lapsa" (2) & $\begin{array}{l}P \text {. syringae } \\
\text { pathovar lapsa }\end{array}$ & Addendum I & Section I & NCPPB 2096 & $\begin{array}{l}\text { Zea sp. hybrid seed, } \\
\text { place and year of } \\
\text { isolation unknown }\end{array}$ & B \\
\hline 55 & "P. maculicola" (47) & $\begin{array}{l}\text { P. syringae } \\
\text { pathovar } \\
\text { maculicola }\end{array}$ & Addendum I & Section I & NCPPB 1776 & $\begin{array}{l}\text { Brassica oleracea var. } \\
\text { botrytis, United } \\
\text { Kingdom, } 1965\end{array}$ & B \\
\hline 56 & $\begin{array}{l}\text { "P. mangiferaeindi- } \\
\text { cae" (62) }\end{array}$ & $\begin{array}{l}X . \text { campestris path- } \\
\text { ovar mangifer- } \\
\text { aeindicae }\end{array}$ & Addendum I & $\begin{array}{l}X . \text { cam- } \\
\text { pestris }\end{array}$ & $\mathrm{NCPPB} 490^{d}$ & $\begin{array}{l}\text { Mangifera indica, place } \\
\text { and year of isolation } \\
\text { unknown }\end{array}$ & B \\
\hline
\end{tabular}


TABLE 1-Continued

\begin{tabular}{|c|c|c|c|c|c|c|c|}
\hline \multirow[b]{2}{*}{$\begin{array}{l}\text { Sequence } \\
\text { no. }\end{array}$} & \multirow[b]{2}{*}{$\begin{array}{l}\text { Species name as } \\
\text { originally described }^{a}\end{array}$} & \multirow[b]{2}{*}{$\begin{array}{l}\text { Name according to } \\
\text { Young et al. }{ }^{b}\end{array}$} & \multicolumn{2}{|c|}{ Classification in: } & \multirow[b]{2}{*}{ Strain } & \multirow[b]{2}{*}{$\begin{array}{l}\text { Host plant or origin and } \\
\text { place and year of isolation }\end{array}$} & \multirow[b]{2}{*}{$\begin{array}{l}\text { Growth } \\
\text { medium }\end{array}$} \\
\hline & & & $\begin{array}{c}\text { Bergey's } \\
\text { Manual of } \\
\text { Determinative } \\
\text { Bacteriology, } \\
\text { 8th ed. }\end{array}$ & $\begin{array}{l}\text { Bergey's } \\
\text { Manual of } \\
\text { Systematic } \\
\text { Bacteri- } \\
\text { ology }\end{array}$ & & & \\
\hline 57 & $\begin{array}{l}\text { "P. mangiferaeindi- } \\
\text { cae" }(62)\end{array}$ & & & & NCPPB 2387 & $\begin{array}{l}\text { Mangifera indica, India, } \\
1970\end{array}$ & $\mathrm{Z5}$ \\
\hline 58 & $\begin{array}{l}\text { "P mangiferaeindi- } \\
\text { cae" }(62)\end{array}$ & & & & NCPPB 2438 & $\begin{array}{l}\text { Mangifera indica, South } \\
\text { Africa, } 1971\end{array}$ & $\mathrm{Z5}$ \\
\hline 59 & $\begin{array}{l}P . \text { marginalis }(\mathrm{AL}) \\
(10)\end{array}$ & $\begin{array}{l}\text { P. marginalis } \\
\text { pathovar alfalfae }\end{array}$ & Section I & Section I & PDDCC $5708^{d}$ & $\begin{array}{l}\text { Medicago sativa, United } \\
\text { States, } 1971\end{array}$ & PAF \\
\hline 60 & $\begin{array}{l}P . \underset{(10)}{\text { marginalis }(\mathrm{AL})} \\
\end{array}$ & $\begin{array}{l}P . \text { marginalis } \\
\text { pathovar } \\
\text { marginalis }\end{array}$ & Section I & Section I & PDDCC $3553^{\mathrm{T}}$ & $\begin{array}{l}\text { Cichorium intybus, } \\
\text { United States, } 1949\end{array}$ & PAF \\
\hline 61 & P. meliae (VL) (54) & & & & NCPPB $3033^{\mathrm{T}}$ & $\begin{array}{l}\text { Melia azedarach, Japan, } \\
1974\end{array}$ & PAF \\
\hline 62 & "P. oryzicola" (39) & $\begin{array}{l}P . \text { syringae } \\
\text { pathovar syringae }\end{array}$ & Addendum I & & NCPPB $388^{f}$ & $\begin{array}{l}\text { Oryza sativa, Hungary, } \\
\text { year unknown }\end{array}$ & B \\
\hline 63 & "P. oryzicola" (39) & & & & NCPPB 1417 & $\begin{array}{l}\text { Oryza sativa, Hungary, } \\
1956\end{array}$ & B \\
\hline 64 & "P. panici"' (28) & $\begin{array}{l}P \text {. syringae } \\
\text { pathovar panici }\end{array}$ & & Section I & NCPPB $1498^{d}$ & Unknown & B \\
\hline 65 & "P. passiflorae" (68) & $\begin{array}{l}\text { P. syringae } \\
\text { pathovar } \\
\text { passiflorae }\end{array}$ & Addendum I & Section I & NCPPB 224 & $\begin{array}{l}\text { Passiflora edulis, New } \\
\text { Zealand, year } \\
\text { unknown }\end{array}$ & B \\
\hline 66 & "P. passiflorae" (68) & & & & NCPPB 1386 & $\begin{array}{l}\text { Passiflora edulis, New } \\
\text { Zealand, } 1962\end{array}$ & B \\
\hline 67 & "P. pastinacae" (14) & $\begin{array}{l}\text { P. marginalis } \\
\text { pathovar } \\
\text { pastinacae }\end{array}$ & Addendum I & Section I & NCPPB $806^{d}$ & $\begin{array}{l}\text { Pastinaca sativa, United } \\
\text { States, } 1959\end{array}$ & B \\
\hline 68 & "P. primulae" (3) & $\begin{array}{l}P \text {. syringae } \\
\text { pathovar } \\
\text { primulae }\end{array}$ & Addendum I & Section I & $\mathrm{NCPPB} 133^{d}$ & $\begin{array}{l}\text { Primula sp., United } \\
\text { States, year unknown }\end{array}$ & B \\
\hline 69 & $\begin{array}{l}\text { P. pseudoalcaligenes } \\
\text { subsp. citrulli (AL) } \\
(78)\end{array}$ & & & Section I & PDDCC 6521 & $\begin{array}{l}\text { Citrullus lanatus, United } \\
\text { States, } 1978\end{array}$ & PAF \\
\hline 70 & $\begin{array}{l}\text { P. pseudoalcaligenes } \\
\text { subsp. citrulli (AL) } \\
(78)\end{array}$ & & & & PDDCC 6522 & $\begin{array}{l}\text { Citrullus lanatus, United } \\
\text { States, } 1977\end{array}$ & PAF \\
\hline 71 & "P. ribicola" (7) & $\begin{array}{l}P \text {. syringae } \\
\text { pathovar ribicola }\end{array}$ & Addendum I & Section I & NCPPB $963^{d}$ & $\begin{array}{l}\text { Ribes aureum, place and } \\
\text { year of isolation } \\
\text { unknown }\end{array}$ & B \\
\hline 72 & $\begin{array}{l}\text { P. rubrilineans (AL) } \\
(41)\end{array}$ & P. rubrilineans & & Section V & NCPPB 359 & $\begin{array}{l}\text { Saccharum officinarum, } \\
\text { Mauritius, year } \\
\text { unknwon }\end{array}$ & $\mathrm{Z5}$ \\
\hline 73 & $\begin{array}{l}\text { P. rubrilineans }(\mathrm{AL}) \\
(41)\end{array}$ & & & & NCPPB $920^{\mathrm{T}}$ & $\begin{array}{l}\text { Saccharum officinarum, } \\
\text { Reunion, } 1960\end{array}$ & B \\
\hline 74 & $\begin{array}{l}\text { P. rubrilineans (AL) } \\
(41)\end{array}$ & & & & NCPPB 1118 & $\begin{array}{l}\text { Saccharum officinarum, } \\
\text { India, } 1961\end{array}$ & PAF \\
\hline 75 & $\begin{array}{l}\text { P. rubrisubalbicans } \\
\text { (AL) (16) }\end{array}$ & P. rubrisubalbicans & Addendum I & Section V & NCPPB $1027^{\mathrm{T}}$ & $\begin{array}{l}\text { Saccharum officinarum, } \\
\text { United States, } 1961\end{array}$ & $\mathrm{Z} 5$ \\
\hline 76 & "P. sesami" (45) & $\begin{array}{l}P \text {. syringae } \\
\text { pathovar sesami }\end{array}$ & Addendum I & Section I & NCPPB $1016^{d}$ & $\begin{array}{l}\text { Sesamum orientale, } \\
\text { Yugoslavia, } 1961\end{array}$ & B \\
\hline 77 & "P. setariae" (55) & $P$. setariae & Addendum I & & NCPPB $1392^{d}$ & $\begin{array}{l}\text { Oryza sativa, Japan, } \\
1955\end{array}$ & B \\
\hline 78 & $\begin{array}{l}P . \text { solanacearum } \\
(\mathrm{AL})(82)\end{array}$ & P. solanacearum & Section III & Section II & NCPPB 173 & $\begin{array}{l}\text { Solanum tuberosum, } \\
\text { Kenya, year unknown }\end{array}$ & $\mathrm{Z} 5$ \\
\hline 79 & $\begin{array}{l}P \text {. solanacearum } \\
\text { (AL) }(82)\end{array}$ & & & & NCPPB 215 & $\begin{array}{l}\text { Lycopersicon } \\
\text { lycopersicum, } \\
\text { Rhodesia, year } \\
\text { unknown }\end{array}$ & $\mathrm{Z5}$ \\
\hline 80 & $\begin{array}{l}P \text {. solanacearum } \\
\text { (AL) (82) }\end{array}$ & & & & NCPPB 253 & $\begin{array}{l}\text { Casuarina equisetifolia, } \\
\text { Mauritius, } 1949\end{array}$ & $\mathrm{Z5}$ \\
\hline 81 & $\begin{array}{l}\text { P. solanacearum } \\
\text { (AL) (82) }\end{array}$ & & & & NCPPB 282 & $\begin{array}{l}\text { Solanum tuberosum, } \\
\text { Colombia, } 1950\end{array}$ & B \\
\hline 82 & $\begin{array}{l}\text { P. solanacearum } \\
\text { (AL) (82) }\end{array}$ & & & & ATCC $11696^{\mathrm{T}}$ & $\begin{array}{l}\text { Lycopersicon } \\
\text { lycopersicum, United } \\
\text { States, year unknown }\end{array}$ & $\mathrm{Z5}$ \\
\hline \multirow[t]{2}{*}{83} & $\begin{array}{l}P . \text { solanacearum } \\
\text { (AL) }(82)\end{array}$ & & & & NCPPB 339 & $\begin{array}{l}\text { Host plant unknown } \\
\text { Israel, year unknown }\end{array}$ & Z5 \\
\hline & & & & & NCPPB 446 & Musa sp., Trinidad, 1957 & $\mathrm{Z5}$ \\
\hline
\end{tabular}


TABLE 1-Continued

\begin{tabular}{|c|c|c|c|c|c|c|c|}
\hline \multirow[b]{2}{*}{$\begin{array}{l}\text { Sequence } \\
\text { no. }\end{array}$} & \multirow[b]{2}{*}{$\begin{array}{l}\text { Species name as } \\
\text { originally described }^{a}\end{array}$} & \multirow[b]{2}{*}{$\begin{array}{l}\text { Name according to } \\
\text { Young et al. }\end{array}$} & \multicolumn{2}{|c|}{ Classification in: } & \multirow[b]{2}{*}{ Strain } & \multirow[b]{2}{*}{$\begin{array}{l}\text { Host plant or origin and } \\
\text { place and year of isolation }\end{array}$} & \multirow[b]{2}{*}{$\begin{array}{l}\text { Growth } \\
\text { medium }\end{array}$} \\
\hline & & & $\begin{array}{l}\text { Bergey's } \\
\text { Manual of } \\
\text { Determinative } \\
\text { Bacteriology } \\
\text { 8th ed. }\end{array}$ & $\begin{array}{l}\text { Bergey's } \\
\text { Manual of } \\
\text { Systematic } \\
\text { Bacteri- } \\
\text { ology }\end{array}$ & & & \\
\hline 84 & $\begin{array}{l}\text { P. solanacearum } \\
\text { (AL) (82) }\end{array}$ & & & & & & \\
\hline 85 & $\begin{array}{l}\text { P. solanacearum } \\
\text { (AL) }(82)\end{array}$ & & & & NCPPB 613 & $\begin{array}{l}\text { Solanum tuberosum, } \\
\text { Brazil, } 1958\end{array}$ & B \\
\hline 86 & $\begin{array}{l}\text { P. solanacearum } \\
\text { (AL) }(82)\end{array}$ & & & & NCPPB 787 & $\begin{array}{l}\text { Musa sp., Costa Rica, } \\
\text { year unknown }\end{array}$ & $\mathrm{Z5}$ \\
\hline 87 & $\begin{array}{l}\text { P. solanacearum } \\
(\mathrm{AL})(82)\end{array}$ & & & & NCPPB 789 & $\begin{array}{l}\text { Musa sp., Honduras, } \\
\text { year unknown }\end{array}$ & $\mathrm{Z} 5$ \\
\hline 88 & $\begin{array}{l}P \text {. solanacearum } \\
\text { (AL) }(82)\end{array}$ & & & & NCPPB 792 & $\begin{array}{l}\text { Tectona grandis, } \\
\text { Malaysia, year } \\
\text { unknown }\end{array}$ & B \\
\hline 89 & $\begin{array}{l}\text { P. solanacearum } \\
\text { (AL) (82) }\end{array}$ & & & & NCPPB 909 & $\begin{array}{l}\text { Solanum tuberosum, } \\
\text { Egypt, } 1961\end{array}$ & $\mathrm{Z5}$ \\
\hline 90 & $\begin{array}{l}P . \text { solanacearum } \\
\text { (AL) (82) }\end{array}$ & & & & NCPPB 1019 & $\begin{array}{l}\text { Lycopersicon } \\
\text { lycopersicum, } \\
\text { Portugal, } 1960\end{array}$ & B \\
\hline 91 & $\begin{array}{l}P \text {. solanacearum } \\
\text { (AL) (82) }\end{array}$ & & & & NCPPB 1029 & $\begin{array}{l}\text { Pelargonium capitatum, } \\
\text { Reunion, } 1961\end{array}$ & $\mathrm{Z} 5$ \\
\hline 92 & $\begin{array}{l}\text { P. solanacearum } \\
(\mathrm{AL})(82)\end{array}$ & & & & Kelman 3 & $\begin{array}{l}\text { Musa sp., Costa Rica, } \\
\text { year unknown }\end{array}$ & $\mathrm{Z} 5$ \\
\hline 93 & $\begin{array}{l}P . \text { solanacearum } \\
(\mathrm{AL})(82)\end{array}$ & & & & Kelman 25 & $\begin{array}{l}\text { Lycopersicon } \\
\text { lycopersicum, North } \\
\text { Carolina, year } \\
\text { unknown }\end{array}$ & $\mathrm{Z5}$ \\
\hline 94 & $\begin{array}{l}P . \text { solanacearum } \\
(\mathrm{AL})(82)\end{array}$ & & & & Kelman 81 & $\begin{array}{l}\text { Solanum tuberosum, } \\
\text { Colombia, year } \\
\text { unknown }\end{array}$ & $\mathrm{Z5}$ \\
\hline 95 & $\begin{array}{l}\text { "P. striafaciens" } \\
\text { (29) }\end{array}$ & $\begin{array}{l}\text { P. syringae } \\
\text { pathovar } \\
\text { striafaciens }\end{array}$ & Addendum I & Section I & NCPPB $1898^{f}$ & Unknown & B \\
\hline 96 & “P. stizolobii" (98) & & Addendum I & & $\begin{array}{l}\text { NCPPB } \\
1024 \mathrm{t}^{\prime}\end{array}$ & $\begin{array}{l}\text { Mucuna deeringianum, } \\
\text { Zimbabwe, } 1961\end{array}$ & B \\
\hline 97 & P. syringae (AL) (96) & $\begin{array}{l}P \text {. syringae } \\
\text { pathovar syringae }\end{array}$ & Section I & Section I & NCPPB $281^{\mathrm{T}}$ & $\begin{array}{l}\text { Syringa vulgaris, United } \\
\text { Kingdom, } 1950\end{array}$ & $\mathrm{Z3}$ \\
\hline 98 & $P$. tolaasii $(\mathrm{AL})(56)$ & P. tolaasii & Section I & Section V & NCPPB $741 t 1$ & $\begin{array}{l}\text { Agaricus bisporus, The } \\
\text { Netherlands, } 1951\end{array}$ & $\mathrm{Z5}$ \\
\hline 99 & $P$. tolaasii (AL) (56) & & & & NCPPB 1116 & $\begin{array}{l}\text { Agaricus bisporus, } \\
\text { United Kingdom, } 1961\end{array}$ & $\mathrm{Z} 5$ \\
\hline 100 & P. tolaasii (AL) (56) & & & & NCPPB 1311 & $\begin{array}{l}\text { Agaricus bisporus, } \\
\text { United Kingdom, } 1962\end{array}$ & $\mathrm{Z} 5$ \\
\hline 101 & P. tolaasii (AL) (56) & & . & & NCPPB $2192^{\mathrm{T}}$ & $\begin{array}{l}\text { Agaricus bisporus, } \\
\text { United Kingdom, } 1965\end{array}$ & $\mathrm{Z5}$ \\
\hline 102 & $P$. tolaasii (AL) (56) & & & & NCPPB 2193 & $\begin{array}{l}\text { Agaricus bisporus, } \\
\text { United Kingdom, } 1968\end{array}$ & $\mathrm{Z5}$ \\
\hline 103 & "P. ulmi" (87) & $\begin{array}{l}P . \text { syringae } \\
\text { pathovar } u l m i\end{array}$ & Addendum I & Section I & NCPPB $632^{d}$ & $\begin{array}{l}\text { Ulmus sp., Yugoslavia, } \\
1958\end{array}$ & $\mathrm{Z5}$ \\
\hline 104 & “P. viburni" (94) & $\begin{array}{l}\text { P. syringae } \\
\text { pathovar viburni }\end{array}$ & Addendum I & Section I & NCPPB $1921^{d}$ & $\begin{array}{l}\text { Viburnum sp. United } \\
\text { States, year unknown }\end{array}$ & $\mathrm{ZS}$ \\
\hline 105 & $\begin{array}{l}P . \text { viridiflava }(\mathrm{AL}) \\
\quad(11)\end{array}$ & $P$. viridiflava & Addendum I & Section I & NCPPB $1248 \mathrm{t} 1$ & $\begin{array}{l}\text { Chrysanthemum } \\
\text { morifolium, United } \\
\text { Kingdom,year } \\
\text { unknown }\end{array}$ & $\mathrm{Z} 5$ \\
\hline 106 & $\begin{array}{l}P . \text { viridiflava (AL) } \\
\text { (11) }\end{array}$ & & & & NCPPB $1810 \mathrm{t} 1$ & $\begin{array}{l}\text { Phaseolus vulgaris, } \\
\quad \text { United Kingdom, } 1965\end{array}$ & $\mathrm{Z5}$ \\
\hline 107 & $\begin{array}{l}P . \text { viridiflava }(\mathrm{AL}) \\
\text { (11) }\end{array}$ & & & & NCPPB 2024 & $\begin{array}{l}\text { Viola tricolor, West } \\
\text { Germany, } 1967\end{array}$ & $\mathrm{Z5}$ \\
\hline 108 & "P. viridilivida" $(9)$ & P. viridilivida & Addendum I & & NCPPB $152 \mathrm{t} 1$ & $\begin{array}{l}\text { Lactuca sativa, United } \\
\text { Kingdom, } 1942\end{array}$ & $\mathrm{Z5}$ \\
\hline 109 & "P. viridilivida" (9) & & & & NCPPB 1923 & $\begin{array}{l}\text { Lactuca sativa, United } \\
\text { States, } 1915\end{array}$ & $\mathbf{Z 5}$ \\
\hline 110 & “P. viridilivida" (9) & & & & NCPPB $1963^{d}$ & $\begin{array}{l}\text { Lactuca sativa, United } \\
\text { States, year unknown }\end{array}$ & $\mathrm{Z5}$ \\
\hline 111 & "P. viticola" (53) & $\begin{array}{l}X . \text { campestris path- } \\
\quad \text { ovar viticola }\end{array}$ & & $\begin{array}{l}X . \text { cam- } \\
\text { pestris }\end{array}$ & NCPPB $2475^{d}$ & Vitis vinifera, India, 1969 & $\mathrm{Z5}$ \\
\hline
\end{tabular}


TABLE 1-Continued

\begin{tabular}{|c|c|c|c|c|c|c|c|}
\hline \multirow[b]{2}{*}{$\begin{array}{l}\text { Sequence } \\
\text { no. }\end{array}$} & \multirow[b]{2}{*}{$\begin{array}{l}\text { Species name as } \\
\text { originally described }\end{array}$} & \multirow[b]{2}{*}{$\begin{array}{l}\text { Name according to } \\
\text { Young et al. }\end{array}$} & \multicolumn{2}{|c|}{ Classification in: } & \multirow[b]{2}{*}{ Strain } & \multirow[b]{2}{*}{$\begin{array}{l}\text { Host plant or origin and } \\
\text { place and year of isolation }\end{array}$} & \multirow[b]{2}{*}{$\begin{array}{l}\text { Growth } \\
\text { medium }\end{array}$} \\
\hline & & & $\begin{array}{l}\text { Bergey's } \\
\text { Manual of } \\
\text { Determinative } \\
\text { Bacteriology, } \\
\text { 8th ed. }\end{array}$ & $\begin{array}{l}\text { Bergey's } \\
\text { Manual of } \\
\text { Systematic } \\
\text { Bacteri- } \\
\text { ology }\end{array}$ & & & \\
\hline 112 & "P. viticola" (53) & & & & NCPPB 2614 & Vitis vinifera, India, 1972 & PAF \\
\hline 113 & "P. viticola" (53) & & & & NCPPB 2616 & Vitis vinifera, India, 1972 & PAF \\
\hline 114 & $\begin{array}{l}\text { "P. vitisn'oodrowii" } \\
\text { (61) }\end{array}$ & $\begin{array}{l}X . \text { campestris path- } \\
\text { ovar vitis- } \\
\text { woodrowii }\end{array}$ & Addendum I & $\begin{array}{l}X . \text { cam- } \\
\text { pestris }\end{array}$ & NCPPB $1014^{d}$ & $\begin{array}{l}\text { Vitis woodrowii, India, } \\
\text { year unknown }\end{array}$ & B \\
\hline 115 & $\begin{array}{l}\text { "P. vitiswoodrowii" } \\
\text { (61) }\end{array}$ & & & & NCPPB 2490 & Vitis vinifera, India, 1970 & $\mathrm{Z} 5$ \\
\hline 116 & $\begin{array}{l}\text { "P. washingtoniae" } \\
\text { (65) }\end{array}$ & & Addendum I & & NCPPB 967 & $\begin{array}{l}\text { Host plant and place of } \\
\text { isolation unknown, } \\
1944\end{array}$ & B \\
\hline 117 & P. woodsii (AL) (83) & P. woodsii & Addendum I & Section V & NCPPB $968^{\mathrm{T}}$ & $\begin{array}{l}\text { Dianthus caryophyllus, } \\
\text { United States, } 1957\end{array}$ & B \\
\hline 118 & P. woodsii (AL) (83) & & & & NCPPB 2157 & $\begin{array}{l}\text { Dianthus barbatus, place } \\
\text { of isolation unknown, } \\
1944\end{array}$ & $\mathrm{Z3}$ \\
\hline 119 & $P$, woodsii (AL) (83) & & & & NCPPB 2441 & $\begin{array}{l}\text { Setcreasea purpurea, } \\
\text { United States, } 1969\end{array}$ & PAF \\
\hline 120 & $\begin{array}{l}X . \text { campestris (AL) } \\
(60)\end{array}$ & $\begin{array}{l}X . \text { campestris path- } \\
\text { ovar campestris }\end{array}$ & $\begin{array}{l}X . \text { cam- } \\
\text { pestris }\end{array}$ & $\begin{array}{l}X . \text { cam- } \\
\text { pestris }\end{array}$ & NCPPB $528^{\mathrm{T}}$ & $\begin{array}{l}\text { Brassica oleracea var. } \\
\text { gemmifera, United } \\
\text { Kingdom, } 1957\end{array}$ & \\
\hline
\end{tabular}

${ }^{a}$ For practical reasons, we used the species names as originally described. (AL), Species listed on the Approved Lists of Bacterial Names (81); (VL), species listed on one of the validation lists. Names in quotation marks are not on either the Approved Lists or any validation list, and they have not been published in the International Journal of Systematic Bacteriology since January 1980. The numbers in parentheses are reference numbers.

${ }^{b}$ See reference 102 .

' The compositions of media B, X, Z3, Z5, and PAF have been described elsewhere $(21,22,30,99)$.

${ }^{d}$ Reference strain according to Young et al. (102).

' $\mathrm{T}=$ type strain

${ }^{f}$ Cotype, reference strain, or neotype strain.

percentage of rRNA binding is not a measure of rRNA cistron homology since it depends not only on base sequence matching, but also on the number of rRNA cistrons per genome, the size of the genome, and the state of replication of the DNA. However, it is a useful parameter to separate taxa with the same $T_{m(e)}$ value. Workers in our research group have shown that the DNA-rRNA hybridization method generally does not allow species separation within an rRNA branch. Therefore, other techniques are required.

Most of the phytopathogenic Pseudomonas species could be placed into one of the following four rRNA branches: the $P$. fluorescens branch, the $P$. solanacearum branch, the $P$. acidovorans branch, and the Xanthomonas branch. The position of each species or strain is discussed briefly below. We included as many type strains as possible. For the species which have not been formally accepted on the Approved Lists or the Validation Lists, we included the reference strains, neotype strains, or cotypes, although we know that they have no taxonomic standing at present. For a number of species only one or a few strains were available.

Phytopathogenic pseudomonads belonging to the $P$. fluorescens rRNA branch. The $P$. fluorescens rRNA branch contains the majority of the phytopathogenic pseudomonads. These organisms are Pseudomonas agarici (four strains studied), Pseudomonas amygdali (three strains), Pseudomonas asplenii (one strain), Pseudomonas caricapapayae (two strains), Pseudomonas cichorii (three strains), Pseudomonas corrugata (three strains), Pseudomonas fuscovaginae (one strain), Pseudomonas marginalis (two strains), ( $P$. marginalis pathovar marginalis and $P$. margin- alis pathovar alfalfae), Pseudomonas meliae (one strain), "Pseudomonas pastinacae" (one strain), the Pseudomonas syringae group (including "Pseudomonas aceris" [one strain], "Pseudomonas antirrhini" [one strain], "Pseudomonas apii" [one strain], "Pseudomonas berberidis" [two strains], "Pseudomonas cannabina" [two strains], "Pseudomonas coronafaciens" [one strain], "Pseudomonas eriobotryae" [one strain], "Pseudomonas lapsa" [one strain], "Pseudomonas maculicola" [one strain], "Pseudomonas oryzicola" [two strains], "Pseudomonas panici", [onestrain], "Pseudomonaspassiflorae"'[twostrains], "Pseudomonas primulae" [one strain], "Pseudomonas ribicola", [one strain], "Pseudomonas sesami" [one strain], "Pseudomonas striafaciens" [one strain], $P$. syringae [one strain], "Pseudomonas ulmi" [one strain], and "Pseudomonas viburni" [one strain]), Pseudomonas tolaasii (five strains), Pseudomonas viridiflava (three strains) and "Pseudomonas washingtoniae" (one strain). Two strains of Pseudomonas cattleyae (strains NCPPB 1874 and PDDCC 3992, but not the type strain) and two strains of " $P$. viridilivida" (strains NCPPB 1923 and NCPPB $152 t_{1}$, but not the strain of Young et al. [102]) also belong in this group (see below). These species are genetically closely related to the following nonphytopathogenic members of this rRNA branch: $P$. aeruginosa, P. fluorescens, Pseudomonas putida, Pseudomonas chlororaphis, Pseudomonas aureofaciens, Pseudomonas stutzeri, Pseudomonas mendocina, Pseudomonas alcaligenes, and Pseudomonas pseudoalcaligenes (22).

It is our opinion that the genus Pseudomonas should be limited to the $P$. fluorescens rRNA branch (22), which 
TABLE 2. DNA base compositions and properties of DNA-rRNA hybrids with labeled reference rRNAs from the type strains of $P$. fuorescens, $P$. solanacearum, $P$. acidovorans, and $X$. campestris

\begin{tabular}{|c|c|c|c|c|c|c|c|c|c|c|c|}
\hline \multirow{4}{*}{$\begin{array}{l}\text { Sequence } \\
\text { no. }\end{array}$} & \multirow{4}{*}{ Species ${ }^{a}$} & \multirow{4}{*}{ Strain } & \multirow{4}{*}{$\begin{array}{c}\mathrm{G}+\mathrm{C} \\
\text { content } \\
\text { (mol\%) }\end{array}$} & \multicolumn{8}{|c|}{ Hybridization with rRNA from: } \\
\hline & & & & \multicolumn{2}{|c|}{$\begin{array}{l}\text { P. fluorescens } \\
\text { ATCC } 13525^{\mathrm{T}} \\
\end{array}$} & \multicolumn{2}{|c|}{$\begin{array}{l}\text { P. solanacearum } \\
\text { ATCC } 11696^{\mathrm{T}}\end{array}$} & \multicolumn{2}{|c|}{$\begin{array}{c}\text { P. acidovorans } \\
\text { ATCC } 15668^{\mathrm{T}}\end{array}$} & \multicolumn{2}{|c|}{$\begin{array}{l}X . \text { campestris }^{2} \\
\text { NCPPB } 528^{\mathrm{T}}\end{array}$} \\
\hline & & & & & $\%$ & & $\%$ & & $\%$ & & $\%$ \\
\hline & & & & $\begin{array}{l}\operatorname{Tm}_{(e)} \\
\left({ }^{\circ} \mathrm{C}\right)\end{array}$ & $\begin{array}{c}\text { rRNA } \\
\text { bind- } \\
\text { ing }\end{array}$ & $\begin{array}{l}T m_{(e)} \\
\left({ }^{\circ} \mathrm{C}\right)\end{array}$ & $\begin{array}{c}\text { rRNA } \\
\text { bind- } \\
\text { ing }\end{array}$ & $\begin{array}{l}T m_{(e)} \\
\left({ }^{\circ} \mathrm{C}\right)\end{array}$ & $\begin{array}{c}\text { rRNA } \\
\text { bind- } \\
\text { ing } \\
\end{array}$ & $\begin{array}{l}\operatorname{Tm}_{(e)} \\
\left({ }^{\circ} \mathrm{C}\right)\end{array}$ & $\begin{array}{c}\text { rRNA } \\
\text { bind- } \\
\text { ing }\end{array}$ \\
\hline 1 & "P. aceris" & NCPPB $958^{b}$ & 61.1 & 78.5 & 0.09 & & & 61.5 & 0.08 & & \\
\hline 4 & $P$. agarici & NCPPB $2289^{\mathrm{T} C}$ & 61.1 & 80.0 & 0.09 & & & 60.5 & 0.07 & & \\
\hline 3 & P. agarici & NCPPB 1999t1 & 59.9 & 78.0 & 0.20 & & & & & & \\
\hline 5 & P. agarici & NCPPB $2471 \mathrm{t} 1$ & 58.8 & 78.5 & 0.18 & & & & & & \\
\hline 6 & P. agarici & NCPPB $2471 \mathrm{t} 2$ & 59.9 & 78.5 & 0.19 & & & & & & \\
\hline 11 & P. amygdali & NCPPB $2607^{\mathrm{T}}$ & 58.5 & 74.5 & 0.13 & 56.5 & 0.07 & & & & \\
\hline 12 & $P$. amygdali & NCPPB 2608 & 57.7 & 75.5 & 0.11 & & & & & & \\
\hline 13 & $P$. amygdali & NCPPB 2610 & 55.2 & 76.0 & 0.09 & & & & & & \\
\hline 16 & "P. antirrhini" & NCPPB 1761 & 60.4 & 78.5 & 0.08 & & & 64.0 & 0.09 & & \\
\hline 17 & "P. apii" & NCPPB $1626^{b}$ & 60.8 & 79.0 & 0.09 & & & 63.0 & 0.08 & & \\
\hline 18 & P. asplenii & NCPPB $1947^{\mathrm{T}}$ & & 79.0 & 0.10 & & & 61.0 & 0.09 & & \\
\hline 20 & "P. berberidis" & NCPPB $2724^{b}$ & 59.7 & 79.0 & 0.11 & & & 62.0 & 0.07 & & \\
\hline 19 & "P. berberidis" & NCPPB 1871 & 60.1 & 78.5 & 0.11 & & & & & & \\
\hline 22 & "P. cannabina" & NCPPB 1410 & 60.3 & 79.0 & 0.08 & & & 61.0 & 0.07 & & \\
\hline 23 & "P. cannabina" & NCPPB 2069 & 59.3 & 78.5 & 0.10 & & & 59.0 & 0.06 & & \\
\hline 25 & P. caricapapayae & NCPPB $1873^{\mathrm{T}}$ & 58.9 & 77.5 & 0.09 & & & & & & \\
\hline 24 & P. caricapapayae & NCPPB 1872 & 59.4 & 79.0 & 0.14 & & & 64.0 & 0.09 & & \\
\hline 30 & $P$. cattleyae & NCPPB 1874 & 63.9 & 78.0 & 0.11 & & & 65.0 & 0.12 & & \\
\hline 31 & $P$. cattleyae & PDDCC 3992 & 57.4 & 76.0 & 0.13 & & & & & & \\
\hline 36 & $P$. cichorii & NCPPB $943^{\mathrm{T}}$ & 58.9 & 78.0 & 0.19 & & & & & & \\
\hline 35 & P. cichorii & NCPPB 906 & $59.7^{d}$ & $76.0^{d}$ & $0.13^{d}$ & & & & & & \\
\hline 37 & P. cichorii & NCPPB 1512 & $60.3^{d}$ & $77.5^{d}$ & $0.13^{d}$ & & & $61.5^{d}$ & $0.09^{d}$ & & \\
\hline 40 & "P. coronafaciens" & NCPPB 1328 & 59.3 & 78.0 & 0.15 & & & & & & \\
\hline 41 & P. corrugata & NCPPB $2445^{\mathrm{T}}$ & 60.8 & 78.0 & 0.13 & 60.5 & 0.07 & & & & \\
\hline 42 & P. corrugata & NCPPB 2447 & 60.8 & 78.0 & 0.10 & & & & & & \\
\hline 43 & P. corrugata & NCPPB 2455 & 58.4 & 77.0 & 0.12 & & & & & & \\
\hline 44 & "P. eriobotryae" & NCPPB $2331^{b}$ & 58.3 & 78.5 & 0.10 & & & & & & \\
\hline 47 & $P$. fluorescens & $\operatorname{ATCC} 13525^{\mathrm{T}}$ & $60.2^{d}$ & $81.0^{d}$ & $0.14^{d}$ & $62.5^{d}$ & $0.09^{d \prime}$ & $61.0^{\prime l}$ & $0.10^{d}$ & $69.0^{d}$ & $0.08^{d}$ \\
\hline 48 & P. fuscovaginae & PDDCC 5939 & 60.3 & 77.5 & 0.12 & & & & & & \\
\hline 54 & "P. lapsa"" & NCPPB $2096^{b}$ & 59.4 & 76.0 & 0.12 & & & & & & \\
\hline 55 & "P. maculicola" & NCPPB 1776 & 61.3 & 80.0 & 0.08 & & & 63.5 & 0.07 & & \\
\hline 59 & $P$. marginalis & PDDCC $5708^{b}$ & 60.1 & 78.5 & 0.16 & & & & & & \\
\hline 60 & P. marginalis & PDDCC $3553^{\mathrm{T}}$ & 59.1 & 77.5 & 0.13 & & & & & & \\
\hline 61 & $P$. meliae & NCPPB $3033^{\mathrm{T}}$ & 57.9 & 77.0 & 0.19 & & & & & & \\
\hline 62 & "P. oryzicola" & NCPPB $388^{\circ}$ & 60.7 & 78.0 & 0.10 & & & 62.5 & 0.09 & & \\
\hline 63 & "P. oryzicola" & NCPPB 1417 & 60.8 & 77.5 & 0.09 & & & 62.5 & 0.09 & & \\
\hline 64 & "P.panici" & NCPPB $1498^{b}$ & 60.7 & 78.5 & 0.09 & & & 60.5 & 0.07 & & \\
\hline 65 & "P. passiflorae", & NCPPB 224 & 59.4 & 77.5 & 0.20 & & & & & & \\
\hline 66 & "P. passiflorae" & NCPPB 1386 & 60.3 & 79.0 & 0.09 & & & 62.0 & 0.10 & & \\
\hline 67 & "P. pastinacae" & NCPPB $806^{b}$ & 62.7 & 80.5 & 0.09 & & & 63.0 & 0.07 & & \\
\hline 68 & $" P$. primulae $"$ & NCPPB $133^{b}$ & 60.4 & 79.0 & 0.08 & & & 63.0 & 0.09 & & \\
\hline 71 & "P. ribicola" & NCPPB $963^{b}$ & 60.6 & 77.5 & 0.05 & & & 63.0 & 0.09 & & \\
\hline 76 & "P. sesami" & NCPPB $1016^{b}$ & 59.4 & 78.0 & 0.09 & & & 60.5 & 0.07 & & \\
\hline 95 & "P. striafaciens" & NCPPB $1898^{\circ}$ & 59.1 & 78.5 & 0.09 & & & 63.0 & 0.09 & & \\
\hline 97 & $P$. syringae & NCPPB $281^{\mathrm{T}}$ & $59.9^{d}$ & $78.0^{d}$ & $0.14^{d}$ & & & $59.0^{d}$ & $0.08^{d}$ & & \\
\hline 101 & P. tolaasii & NCPPB $2192^{\mathrm{T}}$ & 61.3 & 80.0 & 0.14 & & & & & & \\
\hline 98 & P. tolaasii & NCPPB 741t1 & 61.1 & 79.5 & 0.13 & & & & & & \\
\hline 99 & P. tolaasii & NCPPB 1116 & 61.1 & 80.0 & 0.13 & & & & & & \\
\hline 100 & P. tolaasii & NCPPB 1311 & 60.8 & 80.0 & 0.14 & & & & & & \\
\hline 102 & P. tolaasii & NCPPB 2193 & 61.3 & 79.5 & 0.14 & & & & & & \\
\hline 103 & "P. ulmi" & NCPPB $632^{b}$ & 58.7 & 78.5 & 0.09 & & & 63.0 & 0.08 & & \\
\hline 104 & "P. viburni" & NCPPB $1921^{b}$ & 60.1 & 79.0 & 0.10 & & & 62.5 & 0.10 & & \\
\hline 105 & $P$. viridiflava & NCPPB $1248 \mathrm{t} 1$ & & 77.5 & 0.15 & & & & & & \\
\hline 106 & $P$. viridiflava & NCPPB 1810t1 & 59.9 & 77.5 & 0.13 & & & & & & \\
\hline 107 & $P$. viridiflava & NCPPB 2024 & & 77.5 & 0.14 & & & & & & \\
\hline 108 & "P. viridilivida" & NCPPB $152 \mathrm{t} 1$ & 57.4 & 76.0 & 0.13 & & & & & & \\
\hline 109 & "P. viridilivida" & NCPPB 1923 & 61.3 & 77.5 & 0.18 & & & & & & \\
\hline 116 & "P. washingtoniae" & NCPPB 967 & 61.2 & 80.5 & 0.10 & & & 63.0 & 0.09 & & \\
\hline 10 & "P. alliicola" & NCPPB $947^{\mathrm{T}}$ & 67.2 & & & 74.0 & 0.08 & & & & \\
\hline 15 & $P$. andropogonis & NCPPB $934^{T}$ & 59.0 & 64.5 & 0.05 & 74.5 & 0.08 & 71.5 & 0.06 & & \\
\hline 14 & $P$. andropogonis & NCPPB 933 & 61.3 & 65.0 & 0.05 & 75.0 & 0.08 & 72.0 & 0.08 & 59.0 & 0.04 \\
\hline 28 & $P$. caryophylli & NCPPB $2151^{\mathrm{T}}$ & $63.3^{d}$ & $62.0^{d}$ & $0.06^{d}$ & $75.5^{d}$ & $0.09^{d}$ & $70.5^{d}$ & $0.06^{d}$ & & \\
\hline
\end{tabular}


TABLE 2-Continued

\begin{tabular}{|c|c|c|c|c|c|c|c|c|c|c|c|}
\hline \multirow{3}{*}{$\begin{array}{l}\text { Sequence } \\
\text { no. }\end{array}$} & \multirow{3}{*}{ Species $^{a}$} & \multirow{3}{*}{ Strain } & \multirow{3}{*}{$\begin{array}{c}\mathrm{G}+\mathrm{C} \\
\text { content } \\
(\mathrm{mol} \%)\end{array}$} & \multicolumn{8}{|c|}{ Hybridization with rRNA from: } \\
\hline & & & & \multicolumn{2}{|c|}{$\begin{array}{l}\text { P. fluorescens } \\
\text { ATCC } 13525^{\mathrm{T}}\end{array}$} & \multicolumn{2}{|c|}{$\begin{array}{l}\text { P. solanacearum } \\
\text { ATCC } 11696^{\top}\end{array}$} & \multicolumn{2}{|c|}{$\begin{array}{l}P . \text { acidovorans } \\
\text { ATCC } 15668^{\mathrm{T}}\end{array}$} & \multicolumn{2}{|c|}{$\begin{array}{l}\text { X. campestris } \\
\text { NCPPB } 528^{\mathrm{T}}\end{array}$} \\
\hline & & & & $\begin{array}{l}T m_{(e)} \\
\left({ }^{\circ} \mathrm{C}\right)\end{array}$ & $\begin{array}{c}\% \\
\text { rRNA } \\
\text { bind- } \\
\text { ing }\end{array}$ & $\begin{array}{l}T m_{(e)} \\
\left({ }^{\circ} \mathrm{C}\right)\end{array}$ & $\begin{array}{l}\% \\
\text { rRNA } \\
\text { bind- } \\
\text { ing }\end{array}$ & $\begin{array}{l}T m_{\left(e^{\prime}\right)} \\
\left({ }^{\circ} \mathrm{C}\right)\end{array}$ & $\begin{array}{c}\% \\
\text { rRNA } \\
\text { bind- } \\
\text { ing }\end{array}$ & $\begin{array}{c}\operatorname{Tm}_{(e)} \\
\left({ }^{\circ} \mathrm{C}\right)\end{array}$ & $\begin{array}{c}\% \\
\text { rRNA } \\
\text { bind- } \\
\text { ing }\end{array}$ \\
\hline 26 & P. caryophylli & NCPPB 349 & & & & 74.5 & 0.08 & & & & \\
\hline 27 & P. caryophylli & NCPPB 609 & 65.0 & & & 76.5 & 0.07 & & & & \\
\hline 32 & P. cepacia & Ballard $717^{\mathrm{T}}$ & $67.5^{d}$ & $64.0^{d}$ & $0.07^{d}$ & $76.0^{d}$ & $0.08^{d}$ & $72.5^{d}$ & $0.08^{d}$ & & \\
\hline 33 & $P$. cepacia & Stanier 382 & $67.4^{d}$ & $64.5^{d}$ & $0.07^{d}$ & $76.0^{d}$ & $0.09^{d}$ & $71.0^{d}$ & $0.07^{d}$ & & \\
\hline 34 & $P$. cepacia & NCTC 10661 & $66.9^{d}$ & $62.0^{d}$ & $0.04^{d}$ & & & $72.0^{d}$ & $0.08^{d}$ & & \\
\hline 50 & $P$. gladioli & NCPPB $1891^{\mathrm{T}}$ & $68.8^{d}$ & $63.5^{d}$ & $0.06^{d}$ & $76.0^{d}$ & $0.07^{d}$ & $69.5^{d}$ & $0.06^{d}$ & & \\
\hline 52 & $P$. glumae & NCPPB $2981^{T}$ & 68.4 & & & 75.0 & 0.10 & & & & \\
\hline 51 & P. glumae & NCPPB 2391 & 67.7 & & & 75.0 & 0.11 & & & & \\
\hline 75 & P. rubrisubalbicans & NCPPB $1027^{\mathrm{T}}$ & 62.5 & & & 75.0 & 0.07 & 71.0 & 0.08 & & \\
\hline 82 & P. solanacearum & ATCC $11696^{\mathrm{T}}$ & $66.1^{d}$ & $63.0^{d}$ & $0.05^{d}$ & $81.5^{d}$ & $0.08^{d}$ & $72.0^{d}$ & $0.07^{d}$ & $62.5^{d}$ & $0.05^{d}$ \\
\hline $\begin{array}{l}78-81 \\
83-94\end{array}$ & P. solanacearum & & $\begin{array}{l}66.3- \\
68.1^{d}\end{array}$ & & & $\begin{array}{l}80.0- \\
81.5^{d}\end{array}$ & $\begin{array}{l}0.07- \\
0.12^{d}\end{array}$ & $\begin{array}{l}69.5- \\
72.0^{d}\end{array}$ & $\begin{array}{l}0.04- \\
0.07^{d}\end{array}$ & & \\
\hline 96 & "P. stizolobii" & $\mathrm{NCPPB} 1024 \mathrm{t} 2^{e}$ & 59.4 & 65.0 & 0.04 & 74.0 & 0.08 & & & & \\
\hline 117 & P. woodsii & NCPPB $968^{\mathrm{T}}$ & 59.8 & 64.0 & 0.04 & 75.5 & 0.07 & 71.5 & 0.07 & & \\
\hline 118 & P. woodsii & NCPPB 2157 & & & & 75.0 & 0.08 & & & & \\
\hline 119 & P. woodsii & NCPPB 2441 & & & & 75.5 & 0,06 & & & & \\
\hline 2 & P. acidovorans & ATCC $15668^{\mathrm{T}}$ & $66.6^{d}$ & $61.0^{d}$ & $0.07^{d}$ & $70.5^{d}$ & $0.07^{d}$ & $80.5^{d}$ & $0.12^{d}$ & $61.0^{d}$ & $0.04^{d}$ \\
\hline 7 & "P. alboprecipitans" & NCPPB $1011^{T}$ & 70.8 & 63.5 & 0.05 & & & 78.0 & 0.09 & & \\
\hline 8 & "P. alboprecipitans" & NCPPB 2399 & 67.8 & 64.0 & 0.06 & & & 77.0 & 0.07 & & \\
\hline 9 & "P. alboprecipitans", & NCPPB 2401 & 66.6 & & & & & 75.5 & 0.08 & & \\
\hline 29 & P. cattleyae & NCPPB $961^{\mathrm{T}}$ & 68.6 & 61.0 & 0.06 & 70.4 & 0.07 & 73.5 & 0.09 & & \\
\hline 69 & $\begin{array}{l}P . \text { pseudoalcaligenes } \\
\text { subsp. citrulli }\end{array}$ & PDDCC 6521 & 68.1 & 64.0 & 0.07 & 72.5 & 0.06 & 77.0 & 0.07 & & \\
\hline 70 & $\begin{array}{l}P . \text { pseudoalcaligenes } \\
\text { subsp. citrulli }\end{array}$ & PDDCC 6522 & 67.2 & 63.5 & 0.07 & & & 77.0 & 0.08 & & \\
\hline 73 & $P$. rubrilineans & NCPPB $920^{\mathrm{T}}$ & 69.0 & 57.5 & 0.03 & 72.5 & 0.05 & 77.5 & 0.06 & & \\
\hline 72 & P. rubrilineans & NCPPB 359 & 68.1 & & & & & 76.0 & 0.08 & & \\
\hline 74 & $P$. rubrilineans & NCPPB 1118 & 69.6 & & & & & 76.5 & 0.07 & & \\
\hline 77 & "P. setariae" & NCPPB $1392^{b}$ & 69.1 & & & 72.5 & 0.12 & 78.0 & 0.08 & & \\
\hline 120 & $X$. campestris & NCPPB $528^{\mathrm{T}}$ & $65.2^{d}$ & $69.0^{d}$ & $0.07^{d}$ & & & $63.0^{d}$ & $0.06^{d}$ & $81.0^{d}$ & $0.09^{d}$ \\
\hline 21 & $P$. betle & NCPPB $323^{T}$ & 68.7 & 67.0 & 0.09 & & & 59.5 & 0.09 & 79.0 & 0.10 \\
\hline 49 & "P. gardneri" & NCPPB $881^{e}$ & 64.2 & 66.5 & 0.04 & & & 62.0 & 0.04 & 81.0 & 0.05 \\
\hline 53 & P. hibiscicola & NCPPB $1683^{\mathrm{T}}$ & 67.9 & 67.5 & 0.08 & & & 63.5 & 0.11 & 78.0 & 0.09 \\
\hline 56 & "P. mangiferaeindicae", & NCPPB $490^{b}$ & 65.8 & 69.5 & 0.04 & & & 64.0 & 0.05 & 80.5 & 0.05 \\
\hline 57 & "P. mangiferaeindicae", & NCPPB 2387 & 65.7 & & & & & & & 80.0 & 0.07 \\
\hline 58 & "P. mangiferaeindicae" & NCPPB 2438 & 63.9 & & & & & & & 78.0 & 0.06 \\
\hline 111 & "P. viticola" & NCPPB $2475^{b}$ & 65.2 & & & & & & & 80.0 & 0.07 \\
\hline 112 & " $P$. viticola", & NCPPB 2614 & 65.1 & & & & & & & 76.0 & 0.06 \\
\hline 113 & "P. viticola", & NCPPB 2616 & 64.7 & & & & & & & 79.0 & 0.07 \\
\hline 114 & $" P$. vitiswoodrowii" & NCPPB $1014^{b}$ & 65.7 & 69.0 & 0.04 & & & 58.5 & 0.03 & 78.5 & 0.07 \\
\hline 115 & "P. vitiswoodrowii'" & NCPPB 2490 & 65.2 & & & & & & & 79.0 & 0.07 \\
\hline 38 & P. cissicola & NCPPB $2982^{\mathrm{T}}$ & 55.7 & 60.5 & 0.07 & 62.5 & 0.08 & & & & \\
\hline 39 & P. cissicola & PDDCC 4290 & 56.9 & 61.5 & 0.06 & & & & & & \\
\hline 46 & P. flectens & NCPPB $539^{\mathrm{T}}$ & 31.8 & 59.5 & 0.10 & & & 54.5 & 0.09 & & \\
\hline 45 & $P$. flectens & NCPPB 538 & 44.8 & & & 55.0 & 0.13 & & & & \\
\hline 110 & $" P$. viridilivida", & NCPPB $1963^{b}$ & 68.9 & 55.0 & 0.08 & 58.5 & 0.07 & & & & \\
\hline
\end{tabular}

${ }^{a}$ For more information see Table 1.

${ }^{b}$ Reference strain according to Young et al. (102).

${ }^{c} \mathrm{~T}=$ type strain.

${ }^{d}$ Data from reference 22 .

${ }^{e}$ Cotype, reference strain, or neotype strain.

corresponds to Section I of Pseudamonas in Bergey's Manual of Systematic Bacteriology (57). Therefore, all of the above-mentioned phytopathogenic strains and species are authentic members of this genus. The species or pathovar names of these phytopathogenic organisms should be retained as separate entities until future extensive phenotypic and genotypic experiments reveal synonymies, if any. Our findings should induce extensive experimentation on the relationships among these species and pathovars. The $P$. fuorescens rRNA branch contains saprophytes, human and animal pathogens, clinical isolates, epiphytes, and phytopathogens with $T_{m(e)}$ values ranging from 74.5 to $81.0^{\circ} \mathrm{C}$. The $\mathrm{G}+\mathrm{C}$ contents vary between 55.2 and $66.8 \mathrm{~mol} \%$.

Some of our findings agree with data in the literature. In Bergey's Manual of Systematic Bacteriology $P$. syringae, $P$. cichorii, $P$. marginalis, and $P$. tolaasii are classified in Section I of Pseudomonas (57), which belongs completely in the $P$. fluorescens rRNA branch $(22,59)$. Young et al. (102) 

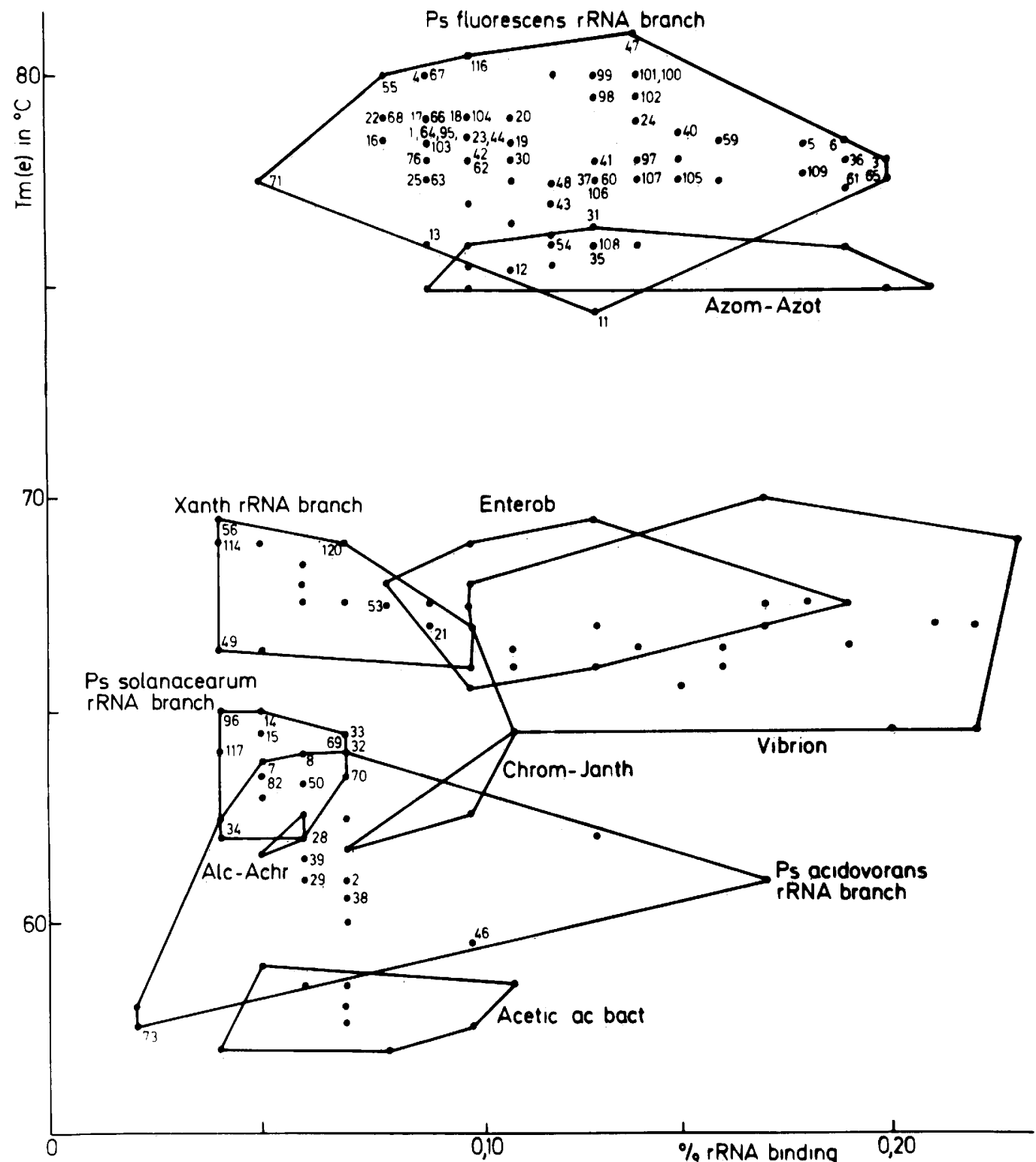

FIG. 2. Similarity map of DNA-rRNA hybrids between the radioactively labeled $23 \mathrm{~S}$ rRNA fraction of $P$. fluorescens ATCC $13525^{\mathrm{T}}$ and DNAs from phytopathogenic Pseudomonas strains (represented by their sequence numbers) (see Tables 1 and 2). Values for hybrids with DNAs from a number of bacteria belonging to different taxa (unmarked symbols) were taken from a previous paper (22). Abbreviations: Ps, Pseudomonas; Azom-Azot, Azomonas-Azotobacter; Xanth, Xanthomonas; Enterob, Enterobacteriaceae; Vibrion, Vibrionaceae; ChromJanth, Chromobacterium-Janthinobacterium; Alc-Achr, Alcaligenes-Achromobacter; Acetic ac bact, acetic acid bacteria.

and Dye et al. (26) proposed 40 to 41 pathovars in $P$. syringae, which is also commonly called the $P$. syringae group. The grouping of these pathovars in one species is at least partially supported by phenotypic (74) and genotypic data (DNA-DNA hybridization) (64). We examined various strains of 19 of the pathovars and localized them without exception in the $P$. fluorescens branch. Lukezic (43) found a level of phenotypic similarity of ca. $80 \%$ between $P$. corrugata and $P$. syringae. The localization of $P$. amygdali by Psallidas and Panagopoulos (66) in group Ia of Lelliott et al. (42) and group IA of Misaghi and Grogan (50) (i.e., the groups containing the pathogen $P$. syringae and related organisms) suggested a close relationship with $P$. fluorescens. $P$. agarici and $P$. asplenii were assigned to group I of Byng et al. (15), who determined relatedness among pseu- domonads and xanthomonads from various enzymic patterns during tyrosine biosynthesis. Group I of Byng et al. (15) corresponds to our $P$. fluorescens rRNA branch. Billing (6) reported that $P$. viridiflava is phenotypically closely related to $P$. syringae. According to Young (101), " $P$. washingtoniae" must be regarded as a synonym of $P$. fluorescens.

The presence or absence of yellowish green fluorescent pigments on King medium $\mathrm{B}$ is considered to be a primary criterion in separating the phytopathogenic pseudomonads for identification $(33,76,79)$. However, this single feature induces identification problems with nonfluorescent strains, which resemble fluorescent strains in several phenotypic features. Our DNA-rRNA hybridization data reveal a quite clear-cut situation. All yellowish green fluorescent pseu- 


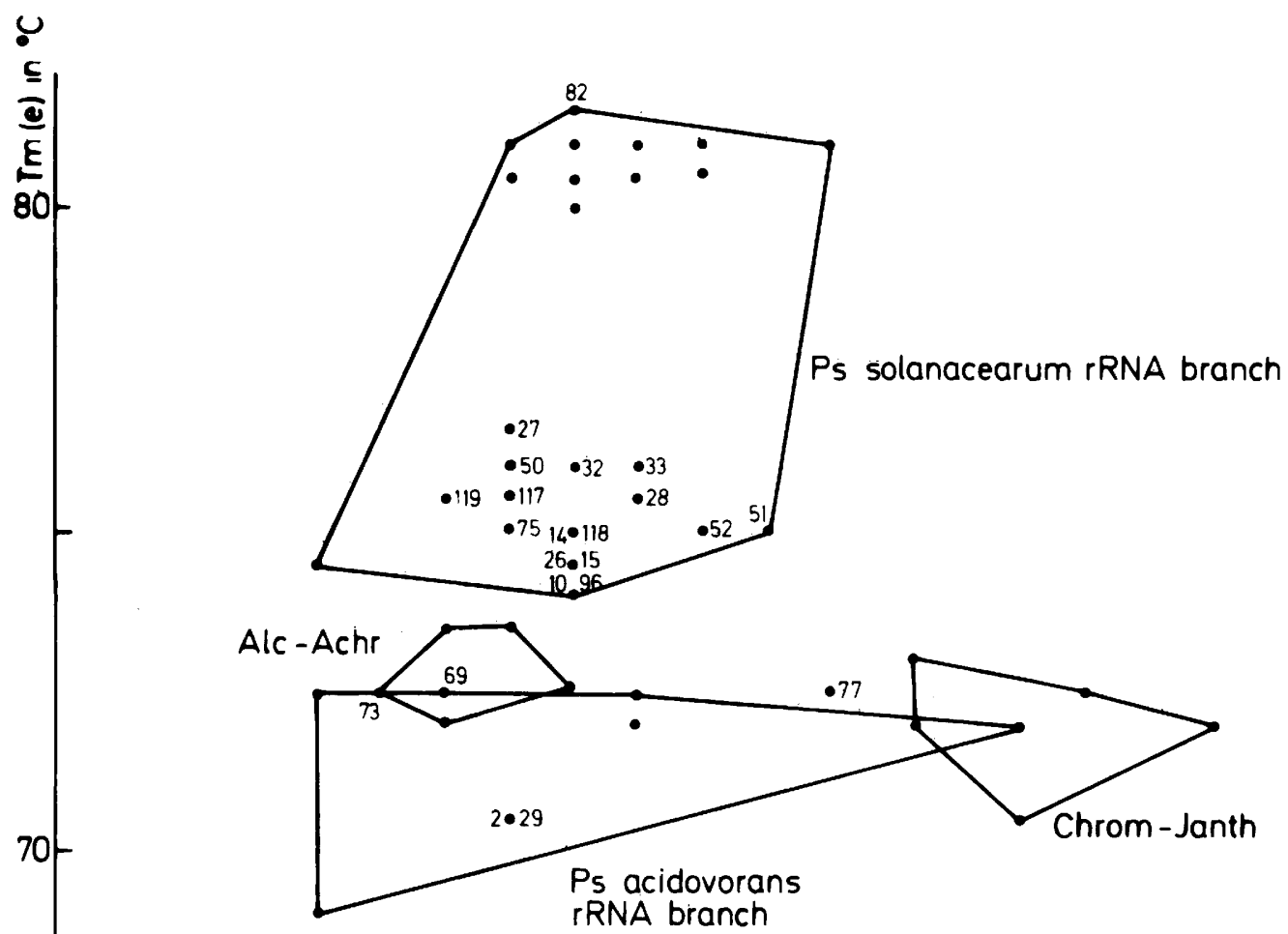

FIG. 3. Similarity map of DNA-rRNA hybrids between the radioactively labeled $23 \mathrm{~S}$ rRNA fraction of $P$. solanacearum ATCC $11696^{\mathrm{T}}$ and DNAs from organisms belonging to different taxa. For further explanation see the legend to Fig. 2. Abbreviations: Ps, Pseudomonas; Alc-Achr, Alcaligenes-Achromobacter; Chrom-Janth, Chromobacterium-Janthinobacterium; Xanth, Xanthomonas; E coli, Escherichia coli.

domonads are genetically related and belong in our $P$. fluorescens rRNA branch. The nonfluorescent phytopathogenic pseudomonads belong to one of the following four genetically different groups: the $\boldsymbol{P}$. fluorescens rRNA branch, the $P$. solanacearum rRNA branch, the $P$. acidovorans rRNA branch or the Xanthomonas rRNA branch. Thus, as far as we know, the $P$. fluorescens rRNA branch contains both fluorescent and nonfluorescent members which are genetically closely related and appear to be different because of only one feature, the production of yellowish green fluorescent pigments. In both the fluorescent non-phytopathogenic and phytopathogenic species of the $P$. fluorescens rRNA branch there are nonfluorescent strains. In this rRNA branch there are also non-phytopathogenic and 


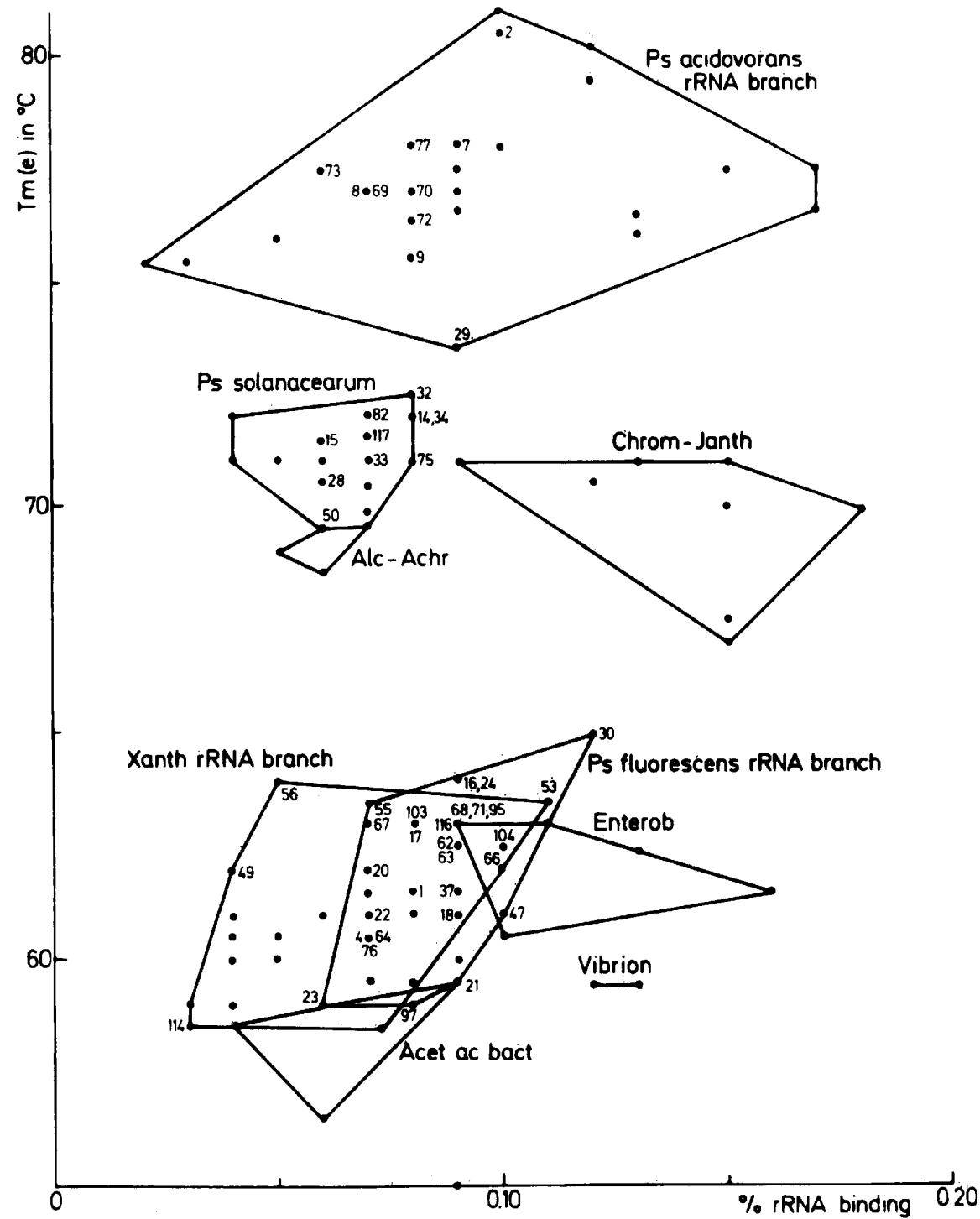

FIG. 4. Similarity map of DNA-rRNA hybrids between the radioactively labeled $23 \mathrm{~S}$ rRNA fraction of $P$. acidovorans ATCC $15668^{\mathrm{T}}$ and DNAs from organisms belonging to different taxa. For further explanation see the legend to Fig. 2. Abbreviations: Ps, Pseudomonas; Chrom-Janth, Chromobacterium-Janthinobacterium; Alc-Achr, Alcaligenes-Achromobacter; Xanth, Xanthomonas; Enterob, Enterobacteriaceae; Vibrion, Vibrionaceae; Acet ac bact, acetic acid bacteria.

phytopathogenic species containing no fluorescent strains; examples of the latter are $P$. amygdali, " $P$. cannabina," $P$. corrugata, $P$. meliae, and "P. sesami." This information should be useful for adapting and improving the present key for identification of phytopathogenic pseudomonads.

Phytopathogenic organisms belonging to the $P$. solanacearum rRNA branch. Together with $P$. solanacearum itself (17 strains studied; $T_{m(e)}$ values, 80.0 to $81.5^{\circ} \mathrm{C}$ ), three other phytopathogenic Pseudomonas species, Pseudomonas cepacia (3 strains; $T_{m(e)}$ value, $76.0^{\circ} \mathrm{C}$ ), Pseudomonas caryophylli (3 strains; $T_{m(e)}$ values, 74.5 to $76.5^{\circ} \mathrm{C}$ ), and Pseudomonas gladioli (1 strain; $T_{m(e)}$ value, $76.0^{\circ} \mathrm{C}$ ), belong to the $P$. solanacearum rRNA branch (22), which corresponds to Section II of Pseudomonas in Bergey's Manual of Systematic Bacteriology (57). Based on phenotypic characterization and DNA-DNA homology studies, "Pseudomonas alliicola" appeared to be a synonym of "Pseudomonas marginata" (5), which was in turn considered to be a subjective synonym of $P$. gladioli (32) on phenotypic grounds. The Young reference strain of " $P$. alliicola" falls in this rRNA branch with a $T_{m(e)}$ value of $74.0^{\circ} \mathrm{C}$, as expected. In addition, Pseudomonas andropogonis (two strains), which is a synonym of "Pseudomonas stizolobii" (one strain) (31), Pseudomonas glumae (two strains), Pseudomonas woodsii (three strains), and the type strain of Pseudomonas rubrisubalbicans (one strain) also belong in the $P$. solanacearum rRNA branch $\left(T_{m(e)}\right.$ values around $75^{\circ} \mathrm{C}$ compared with $P$. solanacearum). At present the classification of the above-mentioned phytopathogenic species within the $P$. solanacearum rRNA branch is not clear.

The $P$. solanacearum rRNA branch now contains 8 to 11 named phytopathogenic Pseudomonas species. We previously stated (22) that this rRNA branch is not related to the authentic pseudomonads. Future extensive studies on the $\boldsymbol{P}$. solanacearum rRNA branch will have to include the species mentioned above.

Phytopathogenic organisms belonging to the $P$. acidovorans rRNA branch. Thus far, the $P$. acidovorans rRNA branch 


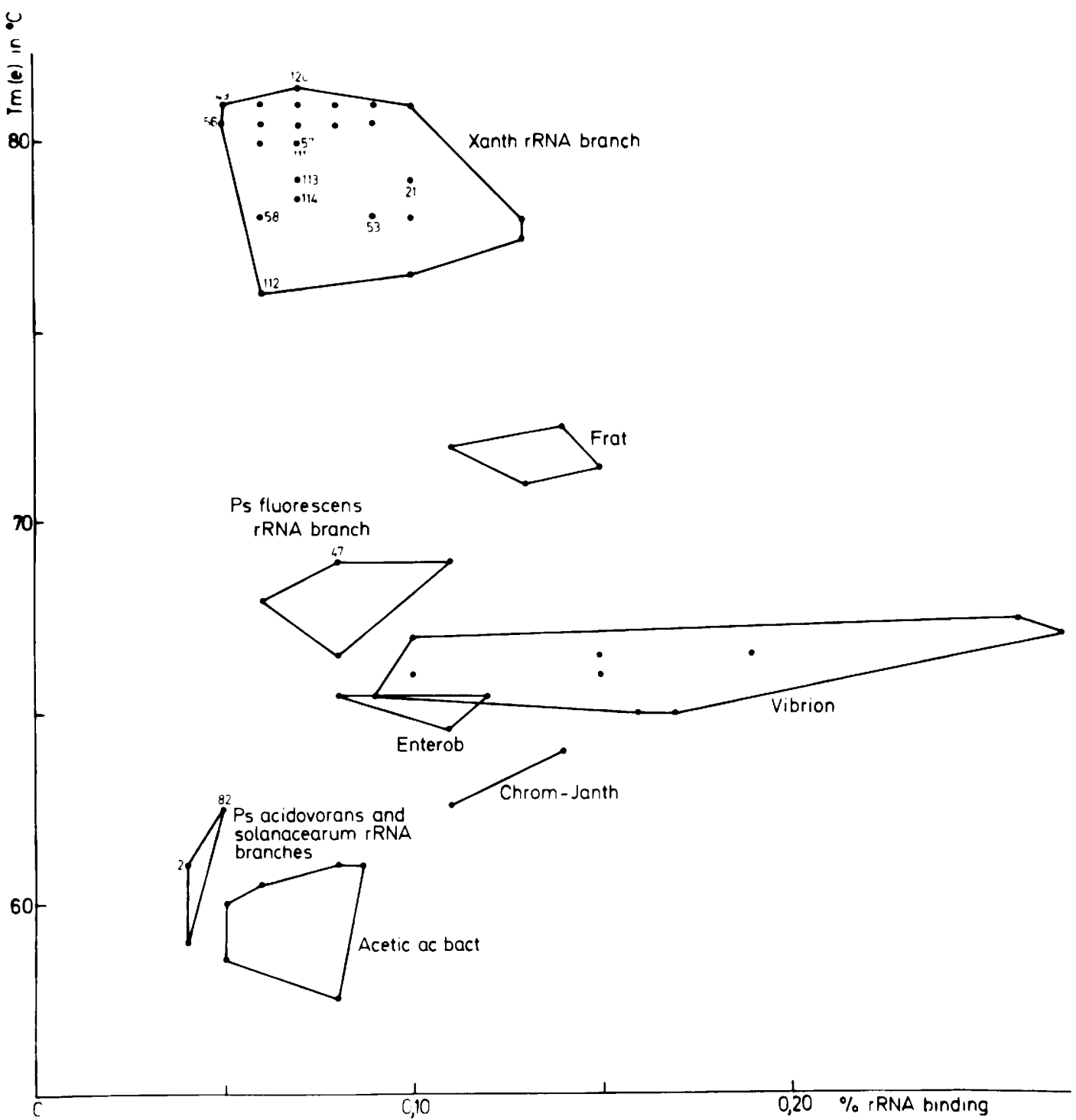

FIG. 5. Similarity map of DNA-rRNA hybrids between the radioactively labeled 23S rRNA fraction of $X$. campestris NCPPB 528 ${ }^{\mathrm{T}}$ and DNAs from organisms belonging to different taxa. For further explanation see the legend to Fig. 2. Abbreviations: Xanth, Xanthomonas; Frat, Frateuria; Ps, Pseudomonas; Enterob, Enterobacteriaceae; Vibrion, Vibrionaceae; Chrom-Janth, Chromobacterium-Janthinobacterium; Acetic ac bact, acetic acid bacteria.

contains only one phytopathogenic species, "Pseudomonas alboprecipitans," which was assigned to it by Byng et al. (15) based on comparative enzymology. Section III of Pseudomonas in Bergey's Manual of Systematic Bacteriology (57) contains no phytopathogens. Our data (Table 2) clearly show that three strains of "P. alboprecipitans" (a subjective synonym of Pseudomonas avenae according to Schaad et al. [77]), P. pseudoalcaligenes subsp. citrulli (two strains), Pseudomonas rubrilineans (three strains), and "Pseudomonas setariae" (one strain) belong to this rRNA branch. Young et al. (102) classified all of these organisms except $P$. pseudoalcaligenes subsp. citrulli among the nonfluorescent plant-pathogenic Pseudomonas species; $P$. pseudoalcaligenes subsp. citrulli had not been described at that time. One would expect the latter taxon to be closely related to $P$. pseudoalcaligenes subsp. pseudoalcaligenes, which belongs to the $P$. fluorescens rRNA branch. However, $P$. pseudoalcaligenes subsp. citrulli (78) is not a member of the $P$. fluorescens rRNA branch $\left(T_{m(e)}\right.$ value, 63.5 to $64^{\circ} \mathrm{C}$ compared with $P$. fluorescens). Therefore, we reject the present classification of the melon pathogens as subspecies of $P$. pseudoalcaligenes. Their exact species status is being investigated in our laboratory and will be reported separately.

It is not surprising that the melon pathogens were erroneously assigned to the $P$. alcaligenes- $P$. pseudoalcaligenes group of Stanier et al. (84). Indeed, these authors (84) reported that this group, as well as the $P$. acidovoransPseudomonas testosteroni (84) group, contained nutritionally restricted bacteria. Assignment of organisms to either one of these groups is based mainly on the absence of physiological and biochemical features and may therefore be questionable.

Schaad et al. (78) mentioned a certain phenotypic resemblance between $P$. pseudoalcaligenes subsp. citrulli and $P$. avenae, which is itself a member of the $P$. acidovorans rRNA branch. This supports our DNA-rRNA hybridization data. One of the major differences was the disagreement in 
$\mathrm{G}+\mathrm{C}$ content $(70$ to $75 \mathrm{~mol} \% \mathrm{G}+\mathrm{C}$ for $P$. avenae and $66 \pm$ $1.6 \mathrm{~mol} \% \mathrm{G}+\mathrm{C}$ for the melon pathogens). However, in our hands the DNA base composition of $P$. avenae (our " $P$. alboprecipitans" strains) was definitely lower (between 70.8 and $66.6 \mathrm{~mol} \% \mathrm{G}+\mathrm{C}$ ), which does not a priori exclude a close relationship between the two taxa.

Phytopathogenic organisms belonging to the Xanthomonas rRNA branch. The present generic definitions of Xanthomonas and Pseudomonas do not allow a sharp separation between these two genera. Unequivocal identification in either one of these genera is difficult for some organisms. Thus, it is possible $(8,57)$ that some of the phytopathogenic pseudomonads in fact belong in the genus Xanthomonas. Recently, workers in our research group proposed to extend the definition of Xanthomonas by including $T_{m(e)}$ values from DNA-rRNA hybridizations performed with rRNA from the type strain of Xanthomonas campestris (89).

Our DNA-rRNA hybridization data revealed that some pseudomonads are misnamed and should be located in the Xanthomonas rRNA branch (Table 2); these organisms are "Pseudomonas gardneri," Pseudomonas betle, Pseudomonas hibiscicola, "Pseudomonas mangiferaeindicae," "Pseudomonas viticola," and "Pseudomonas vitiswoodrowii." For some of these taxa a close relationship with members of the genus Xanthomonas has been mentioned previously. " $P$. gardneri" was considered by Dye (25) to be a synonym of "Xanthomonas vesicatoria," which is itself a pathovar of $X$. campestris $(8,102)$. Byng et al. (15) also assigned this organism to the Xanthomonas group. Robbs et al. (72) classified " $P$. mangiferaeindicae" as $X$. campestris $\mathrm{f}$. $\mathrm{sp}$. mangiferaeindicae, whereas Young et al. (102) and Bradbury (8) considered it a pathovar of $X$. campestris. " $P$. viticola" and " $P$. vitiswoodrowii" have both been classified as pathovars of $X$. campestris $(8,102)$.

On the Approved Lists of Bacterial Names (81) $P$. betle and $P$. hibiscicola were retained as separate Pseudomonas species. Young et al. (102) classified these organisms as atypical plant-pathogenic Pseudomonas species. Our results show that both of these species should be renamed in the genus Xanthomonas. Their correct position in this genus has to be established.

All of our genotypic data on the Xanthomonas rRNA branch have been confirmed by an extensive phenotypic study of the entire genus Xanthomonas (M. Van den Mooter, J. Swings, and J. De Ley, manuscript in preparation). Definite taxonomic and nomenclatural proposals will be made elsewhere.

Phytopathogenic Pseudomonas species with uncertain taxonomical status. Pseudomonas cissicola and Pseudomonas flectens exhibited no relationship with any of the four rRNA branches considered above. P. cissicola was placed in Addendum III to Pseudomonas in Bergey's Manual of Determinative Bacteriology, 8th ed. (23), and in Section V of Pseudomonas in Bergey's Manual of Systematic Bacteriology (57), indicating its uncertain taxonomic status. $P$. flectens was regarded as an atypical member of Pseudomonas by Young et al. (102), and it was not retained in Bergey's Manual of Systematic Bacteriology (57). From our data we conclude that $P$. cissicola and $P$. flectens should definitely be removed from the genus Pseudomonas. Their correct taxonomic positions remain unknown. The two $P$. flectens strains which we used are probably different since their $\mathrm{G}+\mathrm{C}$ contents differed by $13 \mathrm{~mol} \%$.

$P$. cattleyae and " $P$. viridilivida" are discussed together because both of these species contain strains belonging to different rRNA branches. Young et al. (102) placed both of these species in their group of nonfluorescent phytopathogens. However, each species contains at least two strains $(P$. cattleyae NCPPB 1874 and PDDCC 3992, " $P$. viridilivida", NCPPB 152t1 and NCPPB 1923) which form fluorescent pigments and show a close relationship with the $P$. fluorescens rRNA branch $\left(T_{m(e)}\right.$ values, 76.0 to $\left.78.0^{\circ} \mathrm{C}\right)$. The type strain of $P$. cattleyae, strain NCPPB 961, is a member of the $P$. acidovorans rRNA branch, whereas the former type strain of "P. viridilivida," strain NCPPB 1963 (= DSM 50318 ), is gram positive. Thus, it is certainly not a member of the genus Pseudomonas. A more extensive study must be made to draw definite taxonomic conclusions from these findings and to propose the appropriate nomenclatural changes.

\section{ACKNOWLEDGMENTS}

J.D.L. is indebted to the Fonds voor Geneeskundig Wetenschappelijk Onderzoek and to the Instituut tot Aanmoediging van het Wetenschappelijk Onderzoek in Nijverheid en Landbouw for research and personnel grants. M. Goor is indebted to the Instituut tot Aanmoediging van het Wetenschappelijk Onderzoek in Nijverheid en Landbouw for a scholarship.

\section{LITERATURE CITED}

1. Ark, P. A. 1939. Bacterial leaf spot of maple. Phytopathology 29:968-970.

2. Ark, P. A. 1940 . Bacterial stalk rot of field corn caused by Pseudomonas lapsa sp. n. Phytopathology 30:1

3. Ark, P. A., and M. W. Gardner. 1936. Bacterial leaf spot of Primula. Phytopathology 26:1050-1055.

4. Ark, P. A., and C. M. Tompkins. 1946. Bacterial leaf blight of bird's nest fern. Phytopathology 36:758-761.

5. Ballard, R. W., N. J. Palleroni, M. Doudoroff, R. Y. Stanier, and M. Mandel. 1970. Taxonomy of the aerobic pseudomonads: Pseudomonas cepacia, $P$. marginata, $P$. alliicola, and $P$. caryophylli. J. Gen. Microbiol. 60:199-214.

6. Billing, E. 1970. Pseudomonas viridiflava (Burkholder 1930; Clara 1934). J. Appl. Bacteriol, 33:492-500.

7. Bohr, G. W., and J. C. Maloit. 1946. Bacterial spot of native golden currant (Ribes aureum). J. Agric. Res. 73:281-290.

8. Bradbury, J. F. 1984. Genus II. Xanthomonas Dowson 1939 , p. 199-210. In N. R. Krieg and J. G. Holt (ed.), Bergey's manual of systematic bacteriology, vol. 1. The Williams \& Wilkins Co., Baltimore.

9. Brown, N. A. 1915. A bacterial disease of lettuce. J. Agric. Res. 4:475-478.

10. Brown, N. A. 1918. Some bacterial diseases of lettuce. J. Agric. Res. 13:367-388.

11. Burkholder, W. H. 1930. The bacterial diseases of the bean: a comparative study. Mem. Cornell Univ. Agric. Exp. Sta. 127:1-88.

12. Burkholder, W. H. 1942. Three bacterial plant pathogens: Phytomonas caryophylli sp. n., Phytomonas alliicola sp. n., and Phytomonas manihotis (Arthaud-Berthet et Bondar) Viegas. Phytopathology 32:141-149

13. Burkholder, W. H. 1950. Sour skin, a bacterial rot of onion bulbs. Phytopathology 40:115-117.

14. Burkholder, W. H. 1960. A bacterial brown rot of parsnip roots. Phytopathology 50:280-282.

15. Byng, G. S., R. J. Whitaker, R. L. Gherna, and R. A. Jensen. 1980. Variable enzymological patterning in tyrosine biosynthesis as a means of determining natural relatedness among the Pseudomonadaceae. J. Bacteriol. 144:247-257.

16. Christopher, W. N., and C. W. Edgerton. 1930. Bacterial stripe diseases of sugar-cane in Louisiana. J. Agric. Res, 41:259-267.

17. De Ley, J., and J. De Smedt. 1975. Improvements of the membrane filter method for DNA:rRNA hybridization. Antonie van Leeuwenhoek J. Microbiol. Serol. 41:287-307.

18. De Ley, J., P. Segers, and M. Gillis. 1978. Intra- and intergeneric similarities of Chromobacterium and Janthinobacterium ribsosomal ribonucleic acid cistrons. Int. J. Syst. Bacteriol. 
28:154-168

19. den Dooren de Jong, L. E. 1926. Bijdrage tot de kennis van het mineralisatieproces. Nijgh and van Ditmar Uitgevers-Mij, Rotterdam.

20. De Smedt, J., M. Bauwens, R. Tijtgat, and J. De Ley. 1980. Intra- and intergeneric similarities of ribosomal ribonucleic acid cistrons of free-living nitrogen-fixing bacteria. Int. J. Syst. Bacteriol. 30:106-122.

21. De Smedt, J., and J. De Ley. 1977. Intra- and intergeneric similarities of Agrobacterium ribosomal ribonucleic acid cistrons. Int. J. Syst. Bacteriol. 27:222-240.

22. De Vos, P., and J. De Ley. 1983. Intra- and intergeneric similarities of Pseudomonas and Xanthomonas ribosomal ribonucleic acid cistrons. Int. J. Syst. Bacteriol. 33:487-509.

23. Doudoroff, M., and N. J. Palleroni. 1974. Genus I. Pseudomonas Migula 1894, p. 217-243. In R. E. Buchanan and N. E. Gibbons (ed.), Bergey's manual of determinative bacteriology, 8th ed. The Williams \& Wilkins Co., Baltimore.

24. Du Bow, M. S., and T. Ryan. 1977. Host factor for coliphage Q $\beta$ RNA replication as an aid in elucidating phylogenetic relationships: the genus Pseudomonas. J. Gen. Microbiol. 102:263-268.

25. Dye, D. W. 1966. Cultural and biochemical reactions of additional Xanthomonas spp. N. Z. J. Sci. 9:913-919.

26. Dye, D. W., J. F. Bradbury, R. S. Dickey, M. Goto, C. N. Hale, A. C. Hayward, A. Kelman, R. A. Lelliott, P. N. Patel, D. C. Sands, M. N. Schroth, D. R. W. Watson, and J. M. Young. 1975. Proposals for a reappraisal of the status of names of plant-pathogenic Pseudomonas species. Int. J. Syst. Bacteriol. 25:252-257.

27. Elliott, C. 1920. Halo-blight of oats. J. Agric. Res. 19:139-172.

28. Elliott, C. 1923. A bacterial stripe disease of proso millet. J. Agric. Res. 26:151-160.

29. Elliott, C. 1927. Bacterial stripe blight of oats. J. Agric. Res. 35:811-824.

30. Gillis, M., and J. De Ley. 1980. Intra- and intergeneric similarities of the ribosomal ribonucleic acid cistrons of Acetobacter and Gluconobacter. Int. J. Syst. Bacteriol. 30:7-27.

31. Goto, M., and M. P. Starr. 1971. A comparative study of Pseudomonas andropogonis, $P$. stizolobii and $P$. alboprecipitans. Ann. Phytopathol. Soc. Jpn. 37:233-241.

32. Hildebrand, D. C., N. J. Palleroni, and M. Doudoroff. 1973. Synonymy of Pseudomonas gladioli Severini 1913 and Pseudomonas marginata (McCulloch 1921) Stapp 1928. Int. J. Syst. Bacteriol. 23:433-437.

33. Hildebrand, D. C., and M. N. Schroth. 1972. Identification of the fluorescent pseudomonads. In H. P. Maas Geesteranus (ed.), Proceedings of the 3rd International Conference on Plant Pathogenic Bacteria. Wageningen: Centre for Agriculture Publishing and Documentation, The Netherlands.

34. Iizuka, H., and K. Komagata. 1963. An attempt at grouping of the genus Pseudomonas. J. Gen. Appl. Microbiol. 9:73-82.

35. Iizuka, H., and K. Komagata. 1963. Taxonomy of the genus Pseudomonas with special reference to their modes of metabolism of carbon compounds. J. Gen. Appl. Microbiol. 9:83-95.

36. Ikemoto, S., H. Kuraishi, K. Komagata, R. Azuma, T. Suto, and H. Murooka. 1978. Cellular fatty acid composition in Pseudomonas species. J. Gen. Appl. Microbiol. 24:199-213.

37. Jagger, I. C. 1921. Bacterial leaf spot disease of celery. J. Agric. Res. 21:185-188.

38. Johnson, J. C. 1956. Pod twist: a previously unrecorded bacterial disease of French bean (Phaseolus vulgaris L.). Queensl. J. Agric. Sci. 13:127-158.

39. Klement, Z. 1955. A new bacterial disease of rice caused by Pseudomonas oryzicola n. sp. Acta Microbiol. Hung. 2: 265-274.

40. Kurita, T., and H. Tabei. 1967. On the pathogenic bacterium of bacterial grain rot of rice. Ann. Phytopathol. Soc. Jpn. 33:111.

41. Lee, H. A., H. A. Purdy, C. C. Barnum, and J. P. Martin. 1925. A comparison of red-stripe disease with bacterial diseases of sugar-cane and other grasses, p. 64-74. In Red-stripe disease studies. Bulletin of the Experiment Station of the Hawaiian Sugar Planters Association. Hawaiian Sugar Planters
Association, Honolulu.

42. Lelliott, R. A., E. Billing, and A. C. Hayward. 1966. A determinative scheme for the fluorescent plant pathogenic pseudomonads. J. Appl. Bacteriol. 29:470-489.

43. Lukezic, F. L. 1979. Pseudomonas corrugata, a pathogen of tomato isolated from symptomless alfalfa roots. Phytopathology 69:27-31.

44. Lysenko, O. 1961. Pseudomonas-an attempt at a general classification. J. Gen. Microbiol. 25:379-408.

45. Malkoff, K. 1906. Weitere Untersuchungen über die Bakterienkrankheit auf Sesamum orientale. Zentralbl. Bakteriol. Parasitenkd. Infektionskr. Hyg. Abt. 2 16:664-666.

46. Mandel, M. 1966. Deoxyribonucleic acid base composition in the genus Pseudomonas. J. Gen. Microbiol. 43:273-292.

47. McCulloch, L. 1911. A spot disease of cauliflower. Bull. U.S. Bur. Plant Ind. 225:1-15.

48. Meynell, G. G. 1971. Dodecylamine in the isolation of bacterial DNA. Biochim. Biophys. Acta 240:37-38.

49. Migula, W. 1895. Bacteriaceae (Stabchen-bacterien), p. 20-30. In A. Engler and K. Prantl (ed.), Die Naturlichen Pflanzenfamilien, Teil 1, Abt. 1a. W. Engelmann, Leipzig.

50. Misaghi, I., and R. G. Grogan. 1969. Nutritional and biochemical comparisons of plant-pathogenic and saprophytic fluorescent pseudomonads. Phytopathology 59:1436-1450.

51. Miyajima, K., A. Tanii, and T. Akita. 1983. Pseudomonas fuscovaginae sp. nov., nom. rev. Int. J. Syst. Bacteriol. 33: 656-657.

52. Moniz, L. 1963. Leaf spot of apple-blossom. Curr. Sci. 32:177.

53. Nayudu, M. V. 1972. Pseudomonas viticola sp. nov., incitant of a new bacterial disease of grape vine. Phytopathol. Z. 73:183-186.

54. Ogimi, C. 1977. Studies on bacterial gall of chinaberry (Melia Azedarach Lin.), caused by Pseudomonas meliae n. sp. Bull. Coll. Agric. Univ. Ryukyus 24:497-556.

55. Okabe, N. 1934. Bacterial diseases of plants occurring in Formosa. IV. Bacterial brown-stripe of Italian millet. J. Soc. Trop. Agric. (Taiwan) 6:54-63.

56. Paine, S. G. 1919. Studies in bacteriosis. II. A brown blotch disease of cultivated mushrooms. Ann. Appl. Biol. 5:206-219.

57. Palleroni, N. J. 1984. Genus I. Pseudomonas Migula 1894, p. 141-199. In N. R. Krieg and J. G. Holt (ed.), Bergey's manual of systematic bacteriology, vol. 1. The Williams \& Wilkins Co., Baltimore.

58. Palleroni, N. J., R. W. Ballard, E. Ralston, and M. Doudoroff. 1972. Deoxyribonucleic acid homologies among some Pseudomonas species. J. Bacteriol. 110:1-11.

59. Palleroni, N. J., R. Kunisawa, R. Contopoulou, and M. Doudoroff. 1973. Nucleic acid homologies in the genus Pseudomonas. Int. J. Syst. Bacteriol. 23:333-339.

60. Pammel, L. H. 1895. Bacteriosis of rutabaga (Bacillus campestris n. sp.). Iowa State Coll. Agric. Exp. Sta. Bull. 27:130-134.

61. Patel, M. K., and Y. S. Kulkarni. 1951. A new bacterial leaf spot on Vitis woodrowii Stapf. Curr. Sci. 20:132.

62. Patel, M. K., L. Moniz, and Y. S. Kulkarni. 1948. A new bacterial disease of Mangifera indica L. Curr. Sci. 17:189-190.

63. Pavarino, G. L. 1911. Malattie causate da bacteri nelle orchidee. Atti R. Accad. Naz. Lincei Mem. Cl. Sci. Fis. Mat. Nat. 20:233-237.

64. Pecknold, P. C., and R. G. Grogan. 1973. Deoxyribonucleic acid homology groups among phytopathogenic Pseudomonas species. Int. J. Syst. Bacteriol. 23:111-121.

65. Pine, L. 1943. A hitherto unreported disease of the Washington palm. Phytopathology 33:1201-1204.

66. Psallidas, P. G., and C. G. Panagopoulos. 1975. A new bacteriosis of almond caused by Pseudomonas amygdali sp. nov. Ann. Inst. Phytopathol. Benaki (N.S.) 11:94-108.

67. Ragunathan, C. 1928. Bacterial leaf spot of betel. Ann. R. Bot. Gard. Peradeniya (Ceylon) 11:51-61.

68. Reid, W. D. 1938. Grease-spot of passion-fruit. N. Z. J. Sci. Technol. Sect. A 20:260-265.

69. Rhodes, M. E. 1959. The characterization of Pseudomonas fluorescens. J. Gen. Microbiol. 21:221-263.

70. Rhodes, M. E. 1961. The characterization of Pseudomonas 
fluorescens with the aid of an electronic computer. J. Gen. Microbiol. 25:331-345.

71. Robbs, C. F. 1956. Una nova doenca bacteriana do mamoeiro (Carica papaya L.). Rev. Soc. Brasil. Agron. 12:73-76.

72. Robbs, C. F., R. L. D. Ribeiro, and O. Kimura. 1974. Sobre a posicao taxonomica de Pseudomonas mangiferaeindicae Patel et al. 1948, agente causal da "Mancha bacteriana" das folhas da mangueira (Mangifera indica L.). Arq. Univ. Fed. Rural Rio de Janeiro 4:11-14.

73. Rosen, H. R. 1922. A bacterial disease of foxtail (Chaetochloa lutescens). Ann. Mo. Bot. Gard. 9:383-402.

74. Sands, D. C., M. N. Schroth, and D. C. Hildebrand. 1970. Taxonomy of phytopathogenic pseudomonads. J. Bacteriol. 101:9-23.

75. Scarlett, C. M., J. T. Fletcher, P. Roberts, and R. A. Lelliott. 1978. Tomato pith necrosis caused by Pseudomonas corrugata n. sp. Ann. Appl. Biol. 88:105-114.

76. Schaad, N. W. 1980. Laboratory guide for identification of plant pathogenic bacteria. Bacteriological Committee of the American Phytopathological Society, St. Paul, Minn.

77. Schaad, N. W., C. I. Kado, and D. R. Sumner. 1975. Synonymy of Pseudomonas avenae Manns 1905 and Pseudomonas alboprecipitans Rosen 1922. Int. J. Syst. Bacteriol. 25:133-137.

78. Schaad, N. W., G. Sowell, R. W. Goth, R. R. Colwell, and R. E. Webb. 1978. Pseudomonas pseudoalcaligenes subsp. citrulli subsp. nov. Int. J. Syst. Bacteriol. 28:117-125.

79. Schroth, M. N., D. C. Hildebrand, and M. P. Starr. 1981. Phytopathogenic members of the genus Pseudomonas, p. 701-718. In M. P. Starr, H. Stolp, H. G. Trüper, A. Balows, and H. G. Schlegel (ed.), The prokaryotes, vol. 1. SpringerVerlag, Berlin.

80. Severini, G. 1913. Una bacteriosi dell' Ixia maculata e del Gladiolus coluilli. Ann. Bot. (Rome) 11:413-424.

81. Skerman, V. B. D., V. McGowan, and P. H. A. Sneath. 1980. Approved lists of bacterial names. Int. J. Syst. Bacteriol. 30:225-420.

82. Smith, E. F. 1896. A bacterial disease of the tomato, egg plant and Irish potato (Bacillus solanacearum n. sp.). Bull. Div. Veg. Physiol. Pathol. 12:1-28.

83. Smith, E. F. 1911. Bacteria in relation to plant diseases, vol. 2. Carnegie Institute, Washington, D.C.

84. Stanier, R. Y., N. J. Palleroni, and M. Doudoroff. 1966. The aerobic pseudomonads: a taxonomic study. J. Gen. Microbiol. 43:159-271.

85. Sutic, D. 1957. Bakterioze grvenog putlidzana. Posebna Izd. Inst. Zast. Bilja Beograd 6:1-65.

86. Sutic, D., and W. J. Dowson. 1959. An investigation of a serious disease of hemp (Cannabis sativa L.) in Yugoslavia. Phytopathol. Z. 34:307-314.

87. Sutic, D., and Z. Tesic. 1958. Jedna nova bacterioza bresta izazivac Pseudomonas ulmi n. sp. Zast. Bilja 45:13-25.

88. Swingle, D. B. 1925. Center rot of "French endive" or wilt of chicory (Cichorium intybus L.). Phytopathology 15:730.

89. Swings, J., P. De Vos, M. Van den Mooter, and J. de Ley. 1983. Transfer of Pseudomonas maltophilia Hugh 1981 to the genus Xanthomonas as Xanthomonas maltophilia (Hugh 1981) comb. nov. Int. J. Syst. Bacteriol. 33:409-413.

90. Swings, J., M. Gillis, K. Kersters, P. De Vos, F. Gosselé, and J. De Ley. 1980. Frateuria, a new genus for "Acetobacter aurantius." Int. J. Syst. Bacteriol. 30:547-556.

91. Takimoto, S. 1920. On the bacterial leaf-spot of Antirrhinum majus L. Bot. Mag. 34:253-257.

92. Takimoto, S. 1931. Bacterial bud rot of loquat. J. Plant Prot. 18:349-355.

93. Takimoto, S. 1939. Bacterial leaf spot of Cissus japonica Willd. Ann. Phytopathol Soc. Jpn. 9:41-43.

94. Thornberry, H. H., and H. W. Anderson. 1931. Bacterial leaf spot of viburnum. Phytopathology 21:907-912.

95. Thornberry, H. H., and H. W. Anderson. 1931. A bacterial disease of barberry caused by Phytomonas berberidis $\mathbf{n}$. sp. J. Agric. Res. 43:29-36.

96. van Hall, C. J. J. 1902. Bijdragen tot de kennis der Bakterieele Plantenziekten. Coöperatieve Drukkerij-vereeniging "Plantijn." Publisher, Amsterdam, The Netherlands.

97. Van Landschoot, A., and J. De Ley. 1983. Intra- and intergeneric similarities of the rRNA cistrons of Alteromonas, Marinomonas (gen. nov.) and some other gram-negative bacteria. J. Gen. Microbiol. 129:3057-3074.

98. Wolf, F. A. 1920. A bacterial leaf spot of velvet bean. Phytopathology 10:73-80.

99. Wong, W. C., and T. F. Preece. 1979. Identification of Pseudomonas tolaasi: the white line in agar and mushroom tissue block rapid pitting tests. J. Appl. Bacteriol. 47:401-407.

100. Young, J. M. 1970. Drippy gill: a bacterial disease of cultivated mushrooms caused by Pseudomonas agarici n. sp. N. Z. J. Agric. Res. 13:977-990.

101. Young, J. M. 1977. Nomenclatural status of Pseudomonas barkeri (Berridge 1924) Dowson 1943 and Pseudomonas washingtoniae (Pine 1943) Elliott 1951. Request for an opinon. Int. J. Syst. Bacteriol. 27:300-303.

102. Young, J. M., D. W. Dye, J. F. Bradbury, C. G. Panagopoulos, and C. F. Robbs. 1978. A proposed nomenclature and classification for plant pathogenic bacteria. N. Z. J. Agric. Res. 21:153-177. 